\title{
WADA Time to Choose a Side: Reforming the Anti-Doping Policies in U.S. Sports Leagues While Preserving Players' Rights to Collectively Bargain
}

\author{
Warren $\mathrm{Chu}^{*}$
}

\section{INTRODUCTION}

If you were to ask any sports fan whether performance enhancing drugs ("PEDs") are prevalent in any of the major U.S. sports leagues, the answer would likely be a resounding "yes." From Barry Bonds to Lance Armstrong, the specter of doping has hung over American sports for decades, and there has been consistent pressure to ramp up efforts to both deter and catch offenders. ${ }^{2}$ Yet, while the major U.S. sports leagues - such as Major League Baseball (MLB), the National Basketball Association (NBA), and the National Football League (NFL) - have updated their drug policies, they have not signed on to the World Anti-Doping Agency's AntiDoping Code. ${ }^{3}$ To outside observers, the question arises: If American sports leagues

* J.D. Candidate, Columbia Law School, Class of 2021; B.A., University of California, Los Angeles, Class of 2017; 2020-2021 Notes and Articles Editor of the Columbia Journal of Law \& the Arts. Thank you to Professor Petros C. Mavroidis for his guidance and expertise on this subject. My thanks also go out to Kate Garber, Will Reed, Alec Fisher, and the staff of the Columbia Journal of Law \& Arts for their edits and suggestions in refining this Note. Finally, I am very grateful for the constant support and editing from Jessica Y. Lim.

1. Jere Longman \& Marjorie Connelly, Drug Testing; Americans Suspect Steroid Use in Sports Is Common, Poll Finds, N.Y. Times (Dec. 16, 2003), https://perma.cc/RSX3-L9MN (finding that "43 percent of those polled said they believed that at least half of professional athletes in the United States use steroids"); Doping Survey Reveals Public Opinion, Found. FOR GLOB. SpORTS DeV. (Jan. 28, 2014), https://perma.cc/9H56-ZH99 (finding that "U.S. adults believe that as many as 4 in 10 athletes have used PEDs at some point in their careers").

2. Lawrence Donegan, Barry Bonds Found Guilty but Baseball Is Guilty Too, GuARDIAN: SPORTBLOG (Apr. 14, 2011), https://perma.cc/X8DJ-HC2U; Josh Levs, Lance Armstrong's Epic Downfall, CNN (Oct. 22, 2012), https://perma.cc/DG4X-K8GU; David Wharton, U.S. Anti-Doping Authorities Urge Congress To Criminalize Cheating, L.A. TIMES (Feb. 5, 2020), https://perma.cc/AK38EPX9.

3. Matthew Futterman, A New U.S. Law Would Target Doping's Enablers. International Watchdogs Don't Like It., N.Y. TIMES (Nov. 18, 2020), https://perma.cc/Q4Q5-FKT3 (noting that the NFL, the NBA, MLB, and the NHL are "not signatories to the WADA code")

(C) 2021 Chu. This is an open access article distributed under the terms of the Creative Commons Attribution License, which permits unrestricted use, distribution, and reproduction, provided the original author and source are credited. 
are truly serious about catching athletes who use PEDs, then why not sign on to join the world's largest anti-doping agency? ${ }^{4}$

The International Olympic Committee established the World Anti-Doping Agency (WADA) in 1999, in response to the drug scandal that occurred at the 1998 Tour de France. 5 The Agency's Anti-Doping Code (the "WADA Code" or the "Code") $)^{6}$ is designed to be extremely strict and punitive in order to properly deter athletes from doping and affecting the fairness of competitions. ${ }^{7}$ The Code has drawn the ire of many athletes and has implicated privacy concerns, ${ }^{8}$ but remains in place, governing the Olympics, international sporting competitions, and even the Ultimate Fighting Championship. ${ }^{9}$

MLB, the NBA, and the NFL, despite past pressure from Congress and WADA officials, ${ }^{10}$ have continued to monitor their own athletes and collectively bargain with

4. Paul H. Haagen, The Players Have Lost that Argument: Doping, Drug Testing, and Collective Bargaining, 40 NEW ENG. L. REV. 831, 843 (2006) (noting that, during hearings in 2004, "Congress treated every deviation from the WADA model as a sign of a weak commitment to dealing with performance-enhancingdrugs [sic].”)

5. Who We Are, WORLD ANTI-DOPING AGENCY, https://perma.cc/ZCG3-VPH9 (last visited Nov. 2, 2020); Samuel Abt, Drug Scandal Overshadows Tour de France Prologue, N.Y. TiMES (July 12, 1998), https://perma.cc/J784-HSAP ("A masseur for the Festina team, Willy Voet, was arrested late Wednesday night at the French-Belgian border when his car was found to be carrying a large quantity of such banned drugs as steroids and EPO, a chemical that increases red blood corpuscles and thus provides more oxygen for muscles.").

6. World Anti-Doping Agency, World ANTI-Doping Code 2021 (2020), https://perma.cc/2MSA-AKN2 [hereinafter WADA CODE].

7. The strict liability standard under the WADA Code is both considered one of the hallmarks of the Code and seen by critics as too harsh. Under the WADA Code, "[a]n athlete is fully responsible for any prohibited substance found in his body, regardless of the circumstances; the disciplinary body need not establish intent, fault, negligence or knowing use in order to establish a doping violation." Matthew Hard, Caught in the Net: Athletes' Rights and the World Anti-Doping Agency, 19 S. CAL. INTERDISC. L.J. 533,552 (2010). Unlike U.S. sports leagues, the WADA Code places the burden of proof on the athlete to establish any sort of issue with the testing procedure, sample collection process, etc. The penalties are also much more severe under the WADA Code. "The penalty [under the Code] for a first standard doping violation is two-years of ineligibility if the violation is deemed to be unintentional and four-years of ineligibility if it is determined to be intentional." Daniel José Gandert, The WADA Code: Optimal on Paper, 32 MD. J. INT'L L. 274, 299 (2017). Barring exceptional circumstances, this means that even an unintentional consumption will result in years of ineligibility.

8. The "whereabouts" testing rule of the WADA Code, which requires that some athletes provide constant updates on their location, was met with significant criticism when it was introduced. Tennis star Rafael Nadal in 2009 called the tests "intolerable harassment." Christopher Clarey, Nadal Criticizes the Prying of the Testing Program, N.Y. Times (Jan. 28, 2009), https://perma.cc/T2FQ-P5QH.; See also James Halt, Where Is the Privacy in WADA's "Whereabouts" Rule?, 20 MARQ. SPORTS L. REV. 267, 287 (2009) ("[T]he 'whereabouts' rule deprives an athlete of any privacy the athlete may have once enjoyed. The athlete's everyday activities must be chronicled, and there is no place or time that is off limits for a possible drug test.").

9. Code Signatories, WorLd ANTI-DoPING AGENCY, https://perma.cc/S2UL-DGBL (last visited Nov. 2, 2020).

10. See Rob Harris, WADA President Turns Criticism To U.S. Sports Leagues, Associated PreSS (Nov. 1, 2018), https://perma.cc/MNR3-NPWF; George T. Stiefel III, Comment, Hard Ball, Soft Law in MLB: Who Died and Made WADA the Boss?, 56 BUFF. L. REV. 1225, 1227 (2008) ("WADA, Congress, the media, and fans have placed pressure on MLB to adopt policies that conform to the stringent standards of the Code."); Laura S. Stewart, Comment, Has the United States Anti-Doping Agency Gone Too Far? Analyzing the Shift from "Beyond A Reasonable Doubt" To "Comfortable Satisfaction," 13 VILL. SPORTS 
their players' unions to develop drug testing policies that walk a fine line between ensuring effectiveness while minimizing invasiveness. ${ }^{11}$ Collective bargaining has been seen as a weakness among proponents of the WADA Code. Proponents argue that collective bargaining fails to address the players' incentives to negotiate toothless drug policies and the leagues' incentives to ensure that their star players are not implicated in any scandals. ${ }^{12}$ However, these concerns from WADA officials and the American public are overblown. ${ }^{13}$

This Note argues that while U.S. sports leagues have some work to do in order to properly combat doping, the WADA Code is far too draconian and overly punitive to be implemented in American sports. As they stand, the U.S. sports leagues' policies are largely sufficient and should not become any more punitive than they currently are. However, the conflicts of interest involved when leagues and unions develop their own anti-doping policies should be addressed; specifically, the creation of these policies should be entrusted to an independent agency to ensure their unbiased development and implementation. Part I examines the WADA Code, as well as the current anti-doping policies of the NBA, the NFL, and MLB. Part II argues that the major U.S. sports leagues would be ill-advised to adopt the WADA Code to govern themselves because the WADA Code includes significant drawbacks that place unacceptable burdens on athletes' privacy and autonomy, the difference in effectiveness is not significant enough justify the imposition of WADA's restrictions, and doping is not a significant enough problem overall to justify WADA's many drawbacks. Part III suggests that striking a balance between current U.S. sports league policies and the WADA Code by establishing an independent agency that liaises with each sport's players' union and enlists sponsors in the fight against doping. This solution would serve to address some of the issues levied at MLB, the NBA, and the NFL while avoiding the overly punitive and invasive aspects of the WADA Code.

\section{COMPARING THE WADA CODE AND THE BIG THREE}

MLB, the NBA, and the NFL (collectively, the "Big Three") are the three most viewed sports leagues in the United States. ${ }^{14}$ While other U.S. sports leagues would also be affected if their league adopted the WADA Code, this Note will focus on the effects such adoption would have on the Big Three. Currently, the Big Three utilize a Collective Bargaining Agreement system, in which players' unions, on behalf of the players, negotiate the terms of the anti-doping policies with the leagues. ${ }^{15}$ Because of the current collectively bargained system, adopting the WADA Code-

\& ENT. L.J. 207, 219-20 (2006) ("The current doping situation in professional baseball is so pervasive that Congress is reviewing the sport's drug testing policy.").

11. See infra Part I.

12. See Daniel Gandert \& Fabian Ronisky, American Professional Sports Is a Doper's Paradise: It's Time We Make a Change, 86 N.D. L. REV. 813, 834 (2010).

13. See infra Part III.

14. Jeremy Bowman, Which U.S. Sport Had the Highest Viewership in 2018?, YAHOO! FIN. (Dec. 30, 2018), https://perma.cc/QE5L-M5ZK.

15. Stiefel III, supra note 10, at 1229 . 
which requires leagues to retain unilateral power to alter their anti-doping policieswould have a massive impact on American sports. As such, Part I begins by examining the anti-doping measures of the WADA Code and comparing them with the policies of the Big Three to determine whether these U.S. sports leagues' policies are actually significantly less effective at deterring doping than sports leagues that have adopted the WADA Code. ${ }^{16}$ This Part also explores significant criticisms of the WADA Code's enforcement regime and considers whether these criticisms outweigh any advantage that would come with the Big Three's adoption of the WADA Code.

\section{A. THE WADA CODE}

When the World Anti-Doping Agency was founded in 1999, one of their "first major tasks was standardizing the anti-doping policies within the Olympic Movement."17 The goal of standardization led to the creation of the WADA Code, which now governs the Olympic Games, FIFA, other international competitions, and many non-U.S. national sports leagues. ${ }^{18}$ The Code, which first came out in 2003 (with revisions in 2009, 2015, and 2021), has continued to be incredibly "comprehensive, including instructions for how the code is to be implemented, how doping control is to be conducted, how testing and investigations should take place, and how results are to be analyzed and managed." ${ }^{19}$ While WADA is the governing body responsible for the implementation of the Code, the Code's signatories "are responsible for the implementation of applicable Code provisions through policies, statutes, rules, regulations and programs according to their authority and jurisdiction." 20

One of the most important aspects of the Code is that the athlete is subject to "strict liability."21 As defined in the Code, "strict liability" means that an anti-doping organization need not establish intent, fault, negligence, or knowing use of prohibited substances on the athlete's part in order for the athlete to be subject to discipline under the Code. ${ }^{22}$ Instead, if a substance is detected in an athlete's body, the athlete has the burden of proof to rebut the presumption or "establish specified facts or circumstances." 23 A similarly strict liability standard is also present in U.S. sports leagues, meaning that one of the most important aspects of the Code is already present in U.S. sports leagues. ${ }^{24}$ However, although the NFL and MLB require the

16. Gandert \& Ronisky, supra note 12 , at 815.

17. Gandert, supra note 7, at 280.

18. Code Signatories, supra note 9.

19. Gandert, supra note 7, at 280.

20. Code Compliance, WORLD ANTI-DOPING AGENCY, https://perma.cc/52KD-V2YB (last visited Dec. 29, 2020).

21. Gandert, supra note 7 , at 298 .

22. WADA CODE, supra note 6 , at 94.

23. Id. at 17. "[S]pecified facts or circumstances" would entail mitigating factors, such as accidental or unintentional ingestion, which could lessen the sanctions, but would not allow the athlete to escape punishment altogether. Id.

24. The appeals process in the NFL and MLB "is meant to forgive tests that resulted in a false positive generated by a procedural error.” Ryan Dunleavy, Why Suspended Giants' Golden Tate Is 
league to prove that any adverse test was obtained through proper protocols, ${ }^{25}$ the WADA Code places the burden of proof on an athlete alleging improper testing protocols. $^{26}$

One aspect of the WADA Code that differs sharply from U.S. sports league policy is the length of the punishments. Under the WADA Code, an athlete who fails a doping test and is found to have intended to cheat is subject to a period of ineligibility of four years. ${ }^{27}$ An athlete acts "intentionally" when they "engage in conduct which they knew constituted an anti-doping rule violation or knew there was a significant risk that the conduct might constitute or result in an anti-doping rule violation and manifestly disregarded that risk." 28 The punishment does not take into account which illicit substance the violation involved. ${ }^{29}$ If the violation is deemed to be unintentional, the period of ineligibility is two years, unless the athlete can show No

Unlikely To Win His Appeal, NJ.COM (July 28, 2019), https://perma.cc/D4G5-2RK7. The zero-tolerance policy means that generally regardless of the circumstances, unless there was an error in procedure, the suspension will stand. Id. Golden Tate, an NFL player, self-reported an unintentional violation due to a fertility treatment and was still suspended for four games. Id.

25. Nat'L Football League Players Ass'N, Policy on Performance-Enhancing SuBSTANCES 2020, at 14 (2020), https://perma.cc/R8Z3-TWCG [hereinafter NFL POLICY]; MAJOR League Baseball, Major League Baseball's Joint Drug Prevention and TREatMent Program 50 (2020), https://perma.cc/B5QM-MM49 [hereinafter MLB PROGRAM]. Richard Sherman, an NFL cornerback, successfully had a four-game suspension overturned based on errors in the chain of custody during his test. The tester was found to have omitted a significant event in his report about the testing and thus did not meet the burden of proving the test was properly administered. Lindsay H. Jones, Seahawks' Richard Sherman Wins Appeal of NFL Suspension, USA TODAY (Dec. 27, 2012), https://perma.cc/BEM6CJ5R.

26. This issue was recently in the news as Sun Yang, a famous Chinese swimmer, was suspended for eight years after he smashed a vial of blood that WADA testers had arrived to collect. Audrey McNamara, Chinese Olympic Swimmer Sun Yang Handed 8-Year Ban in Doping Case, CBS News (Feb. 28, 2020), https://perma.cc/9CEF-P8F3. Sun claimed that the "inspectors drawing blood and urine samples failed to have proper identification papers," which swimming world body FINA saw as a violation of anti-doping protocol, rendering the attempted testing "void and invalid." Graham Dunbar, Chinese Swimming Star Defends Failure To Take Doping Test, Associated PrESS (Nov. 15, 2019), https://perma.cc/3RUE-QA3Z. WADA brought a complaint to the Court of Arbitration for Sport (CAS), which found that "[t]he athlete failed to establish that he had a compelling justification to destroy his sample collection containers and forgo the doping control when, in his opinion, the collection protocol was not in compliance." Victor Mather, Karen Crouse \& Tariq Panja, Sun Yang, Chinese Olympic Swimmer, Gets 8-Year Doping Ban, N.Y. TIMES (Feb. 28, 2020), https://perma.cc/39AE-JRJJ.

27. WADA CODE, supra note 6, at 35 .

28. Id. If an athlete tests positive for a banned substance, the burden of proof is on the athlete to prove that their offense was unintentional. In order to do so, the athlete generally must demonstrate to the hearing panel (from the appropriate national doping organization or the Court of Arbitration for Sport) how the Prohibited Substance entered their system unintentionally. WADA CODE, supra note 6, at 34. This is fact-dependent, and the ultimate determination of intent relies on how the hearing panel sees the facts. Id. It should also be noted that the Court of Arbitration for Sport, which handles all positive doping test appeals, does not have a stare decisis doctrine, so it is hard for athletes to predict whether or not their case will be successful on appeal to CAS, as each case may have a different outcome depending on the composition of the panel. Annie Bersagel, Is There a Stare Decisis Doctrine in the Court of Arbitration for Sport? An Analysis of Published Awards for Anti-Doping Disputes in Track and Field, 12 PEPP. DISP. RESOL. L.J. 189, 206 (2012) ("CAS panels follow past awards, but do not regard precedent as binding.").

29. WADA CODE, supra note 6, at 34-35. 
Significant Fault or Negligence, ${ }^{30}$ in which case ineligibility may be reduced by a maximum of one year for a minimum ineligibility of one year. ${ }^{31}$ If the violation involves a "Specified Substance,"32 as defined in the Code, or a contaminated product, ${ }^{33}$ and if the athlete can demonstrate No Significant Fault or Negligence, then ineligibility may range from a reprimand to a two-year suspension (depending on the level of fault). ${ }^{34}$ If an athlete can prove that they bear No Fault or Negligence, the ineligibility period will be eliminated. ${ }^{35}$ However, this only applies in "exceptional circumstances, for example, where an Athlete can prove that, despite all due care, he or she was sabotaged by a competitor." 36 No Fault or Negligence and No Significant Fault or Negligence are rarely successfully invoked; generally, if an athlete tests positive for a prohibited substance, they will face some punishment. ${ }^{37}$

Because the WADA Code has such lengthy suspension baselines, even mitigated punishments end up taking years out of an athlete's career, surpassing even the lengths of full punishments handed down by the Big Three U.S. sports leagues. ${ }^{38}$ Because the length of each punishment applies equally to all athletes, the actual harm

30. The WADA Code defines "No Significant Fault or Negligence" as: "The Athlete or other Person's establishing that any fault or negligence, when viewed in the totality of the circumstances and taking into account the criteria for No Fault or Negligence, was not significant in relationship to the antidoping rule violation." $C f$. infra note 35 (defining "No Fault or Negligence"). The athlete must also establish how the substance entered their system. WADA CODE, supra note 6, at 92.

31. Id.

32. The WADA Code defines "Specified Substances" as: "substances and methods which are more likely to have been consumed or used by an Athlete for a purpose other than the enhancement of sport performance." Id. at 19. If an athlete tests positive for a Specified Substance, the burden is on the doping prosecutors to prove that the athlete acted with intent. It should be noted that an athlete who takes a Specified Substance must still establish they had No Significant Fault or Negligence in order to reduce their punishment. Gandert, supra note 7, at 305.

33. A contaminated product is most often a supplement that contains a prohibited substance. If an athlete takes a supplement that is contaminated with a prohibited substance, the athlete must prove they tested positive as a result of taking a supplement containing a substance "that is not disclosed on the product label or in information available in a reasonable Internet search." WADA CODE, supra note 6, at 90. The athlete must then also prove that they had No Significant Fault or Negligence. No Significant Fault or Negligence has almost never been applied in cases involving contaminated substances. Id. at 37.

34. Id.

35. The WADA Code defines "No Fault or Negligence" as: "The Athlete or other Person's establishing that he or she did not know or suspect, and could not reasonably have known or suspected even with the exercise of utmost caution, that he or she had used or been administered the Prohibited Substance or Prohibited Method or otherwise violated an anti-doping rule." Id. at 92.

36. Id. at 37 .

37. In 2017 , only $4 \%$ of athletes who tested positive for a prohibited substance received "no sanction." World ANTI-DOPING AGENCY, 2017 ANTI-DOPING RULE Violations (ADRVs) REPORT (2019), https://perma.cc/66UT-T8XB [hereinafter ADRVs REPORT]. See also Matthew Hard, Note, Caught in the Net: Athletes' Rights and the World Anti-Doping Agency, 19 S. CAL. INTERDISC. L.J. 533, 552-53 (2010) ("WADA offers a chance to reduce the period of ineligibility based on exceptional circumstances under Article 10.5. These circumstances must show that the athlete either has (1) no fault or negligence, in which case the ineligibility period will be eliminated, or (2) no significant fault or negligence .... The Code is clear that 10.5 is meant to 'have an impact only in cases where the circumstances are truly exceptional and not in the vast majority of cases."').

38. NFL POLICY, supra note 25, at 17; MLB PROGRAM, supra note 25, at 37; NAT'L BASKETBALL Players Ass'N, NBA-NBPA COllective Bargaining Agreement 441-42 (2017), https://perma.cc/44Q2-FCVE [hereinafter NBA AGREEMENT]. 
caused by these suspensions will vary by sport. For example, endurance runners and gymnasts have short athletic primes; for them, a two-year suspension for an accidental ingestion could effectively mean the end of their career. This whole punishment regime is extremely athlete-unfriendly, but the drafters of the WADA Code consider these punishments necessary to properly deter doping; by completely disregarding any extenuating circumstances, the Code theoretically encourages all athletes to remain constantly vigilant. ${ }^{39}$ But, as this Note argues, the actual deterrent effect is currently impossible to measure; therefore, leagues should err on the side of protecting athletes from such overly punitive actions.

WADA's random testing is also much more invasive than that of U.S. sports leagues. The WADA Code sets out that "[a]n athlete may be required to provide a Sample at any time and at any place by any Anti-Doping Organization with Testing authority over him or her." 40 Unlike in U.S. sports leagues, "[t]here is no limit to the number of times an athlete can be tested each year including in-competition, out of competition, random and target testing." 41 There is also no distinction between urine or blood samples; either may be collected at any time or place for analysis. ${ }^{42}$ Additionally, the "highest-priority athletes," as established by international federations or national anti-doping agencies, are included in a registered testing pool, which means that for each quarter of the year, they must provide the agency detailed location information, known as "whereabouts information." 43 These controversial "whereabouts" rules include filing information on "regularly scheduled activities and a one-hour window each day where [they] must be available for testing. The activities and testing window must be kept updated." 44 If an athlete in a registered pool is not where they said they would be during the one-hour window, that is considered a missed test, and three missed tests within a 12-month period are deemed an anti-doping rule violation. ${ }^{45}$ Commentators have noted that "surprise and nonotice testing serve as the cornerstone of [the WADA Code]." 46 Whereabouts testing has been controversial due to the fact that it subjects elite athletes to near constant monitoring and the fact that three missed tests could result in a two to four year suspension. $^{47}$ It has also led to legal challenges on the basis of privacy violations and led many high-profile athletes to "openly voice[] their disdain and contempt for WADA's 'whereabouts' rule through the media." 48 This sort of monitoring is not a

39. WADA CODE, supra note 6 , at 8 .

40. Id. at 24

41. Play True Quiz, WORLd ANTI-DOPING AGENCY (2018), https://perma.cc/8ZB4-8CAT.

42. WADA CODE, supra note 6 , at 27 .

43. Id. at 25,93 .

44. World Anti-Doping Agency, Athlete Reference Guide to the 2015 World AntiDOPING CODE 8 (2015), https://perma.cc/8QMU-Q79A.

45. WADA CODE, supra note 6 , at 14 .

46. Halt, supra note 8, at 269.

47. The WADA Code mandates that every athlete subject to whereabouts testing provide "one specific 60-minute time slot where he/she will be available at a specific location" every day, seven days a week, 365 days a year. WORLD ANTI-DOPING AGENCY, THE WORLD ANTI-DOPING CODE INTERNATIONAL STANDARD: TESTING AND INVESTIGATIONS 76 (2020), https://perma.cc/L76Y-B73P [hereinafter WADA CODE, TESTING \& INVESTIGATIONS].

48. Halt, supra note 8 , at 275 . 
part of U.S. sports leagues' anti-doping policies and is one of the starkest differences between those policies and the WADA Code.

WADA also allows athletes to obtain Therapeutic Use Exemptions ("TUEs") to use prohibited substances for medical purposes ${ }^{49}$ and as with the NFL and MLB, they must be obtained in advance and cannot be obtained retroactively, absent exceptional circumstances. ${ }^{50}$ There is criticism regarding the practice of allowing athletes to gain these exemptions for therapeutic use, with some arguing that athletes taking an otherwise prohibited substance under a TUE are "engaged in doping, but [it's] just that they have permission to do so." ${ }^{51}$ As it stands, TUEs remain an important part of both the WADA Code and U.S. sports leagues anti-doping policies.

\section{B. The NBA Agreement}

The NBA's anti-doping policies are outlined in the NBA-NBPA Collective Bargaining Agreement ("NBA Agreement"). The NBA can test any player, as long as the league has reasonable cause to believe the player is engaged in the use, possession, or distribution of a prohibited substance. ${ }^{52}$ Additionally, the NBA has a random testing program, in which any randomly selected player will undergo testing for prohibited substances; but no individual player will be selected for testing more than four times in a given season and no more than two times in an offseason. ${ }^{53}$ Players are also subject to random human growth hormone ("hGH") blood testing no more than two times during a regular season and no more than one time in an offseason. ${ }^{54}$ Unlike the WADA Code, under which blood testing can occur at any time,${ }^{55}$ the NBA Agreement specifies that if a player is selected for random testing on a day he is scheduled to play in a game, any blood testing must occur after the

49. To obtain a TUE, an athlete must show, on the balance of probabilities that: (1) the prohibited substance "is needed to treat a diagnosed medical condition supported by relevant clinical evidence"; (2) the prohibited substance "will not ... produce any additional enhancement of performance beyond what might be anticipated by a return to ... normal state of health"; (3) the prohibited substance "is an indicated treatment for the medical condition, and there is no reasonable permitted Therapeutic alternative"; and (4) the necessity for the use "is not a consequence, wholly or in part, of the prior use" of a prohibited substance or method. WORLd ANTI-Doping AgEncy, The World ANTI-Doping CODE INTERNATIONAL STANDARD: THERAPEUTIC USE EXEMPTIONS 10-11 (2021), https://perma.cc/B2YR-VM8L.

50. Id.

51. TUE System Can Be Abused by Athletes_-Dr. Richard McLaren, BBC SPORT (Sept. 16, 2016), https://perma.cc/7ZFN-7TME; H.G., A Doper's Dupe? How Athletes Can Use Medical Exemptions To Beat Drug Testers, ECONOMIST (Sept. 19, 2016), https://perma.cc/62M3-DF5A.

52. The NBA separates "Prohibited Substances" into four categories: (1) drugs of abuse (cocaine, Benzodiazepines, etc.); (2) marijuana; (3) steroids and performance enhancing drugs ("SPEDs"); and (4) diuretics (designed to mask performance enhancing drugs). NBA AGREEMENT, supra note 38, Exhibit I-

2. This section of the Note focuses on SPEDs and diuretics.

53. Id. at 433 .

54. Id. at 452 .

55. WADA CODE, supra note 6 , at 27. 
game has concluded. ${ }^{56}$ The NBA conducts a maximum of 1,525 total tests during the season and a maximum of 600 total tests in the offseason. ${ }^{57}$

A test is considered "positive" for a Steroid and Performance Enhancing Drug ("SPED") if: (1) the test is confirmed by laboratory analysis; (2) a player refuses to submit to a random test or cooperate fully with the testing process, without a reasonable explanation; (3) the player refuses to submit to a scheduled test, without a reasonable explanation; (4) the player attempts to substitute, dilute, or adulterate a specimen sample or in any other manner alter a test result; or (5) the test is positive for a diuretic, confirmed by laboratory analysis. ${ }^{58}$ There is a provision of the NBA Agreement that allows an athletes to offer "a reasonable explanation" after the test, which could potentially include a medical explanation for using the prohibited substance, but the provision does not make this clear. ${ }^{59}$ The NBA also allows players to offer "clear and convincing" evidence of no significant fault or negligence that led to the presence of the SPED in their system, in which case an arbitrator may reduce or rescind the penalty otherwise applicable. ${ }^{60}$ No significant fault or negligence would be found in "the unusual circumstance in which the Player did not know or suspect, and could not reasonably have known or suspected, even with the exercise of considerable caution and diligence, that he was taking, ingesting, applying, or otherwise using the ... SPED." 61

For a first positive test, a player is suspended for twenty-five games and entered into the SPED Program. ${ }^{62}$ The SPED Program is run by the SPED Medical Director and includes a number of discretionary measures such as random testing for SPEDs and diuretics. ${ }^{63}$ For a second offense, the player is suspended for fifty-five games, and if he is not still in the SPED Program, he is required to enter it. ${ }^{64}$ For a third offense, the player is "immediately dismissed and disqualified from any association with the NBA and any of its Teams ... for a period of not less than two (2) years." ${ }^{\prime 65}$ These suspensions are much shorter than those in the WADA Code; the NBA's harshest punishment matches the WADA Code's minimum punishment for unintentional doping. Still, the first-offense suspension amounts to $31 \%$ of the

56. NBA AGREEMENT, supra note 38 , at 428 . This is likely done to address concerns that drawing blood may affect athletic performance.

57. Id. at 433 .

58. Id. at 429-30.

59. There is no provision for TUEs or medical exemptions explicitly laid out in the NBA Agreement, but this excerpt could be read to suggest that a medical exemption may be granted retroactively: "If the Medical Director or SPED Medical Director (as applicable) determines, in his professional judgment, that there is a valid alternative medical explanation for such positive test result, then the test shall be deemed negative." Id. at 430.

60. Id. at 457 .

61. Id. at 458 .

62. Id. at 441. The first SPED suspension in the NBA was for five games. Heat Forward MacLean Suspended for Steroids, L.A. TIMES (Nov. 30, 2000), https://perma.cc/P2B9-ZCWF. The 2011 Collective Bargaining Agreement raised the punishment to twenty games for a first SPED violation. NAT'L Basketball Players Ass'N, NBA Collective Bargaining Agreement 355 (2011), https://perma.cc/N4LQ-232L.

63. NBA AGREEMENT, supra note 38 , at 441.

64. Id. at 442 .

65. Id. at 442,445 . 
NBA's 82-game season. To date, the NBA has not had to suspend an athlete for a second SPED offense. ${ }^{66}$ In fact, the two most recent suspensions in the NBA involved allegedly contaminated supplements and unintentional ingestion of a diuretic, ${ }^{67}$ which are quite distinct from deliberate SPED use.

While the majority of the NBA's anti-doping policy is comparable to other U.S. sports leagues, it has often been criticized as being comparatively weak and insufficient because the NBA tests much less frequently than either MLB or the NFL. ${ }^{68}$ However, the relatively low number of tests is likely due to the fact that the NBA has been implementing anti-drug policies since 1983, when the main target was rampant cocaine use; and it is likely that the longevity of the program has helped to establish an effective anti-drug culture among current players. ${ }^{69}$ The focus of the NBA program is directed "most centrally at drugs of abuse," so, "[u]nlike the WADA Code, which is entirely punitive, the relevant NBA program ha[s] significant treatment and counseling elements." testimony before Congress in 2005, NBA officials have made the case that performance-enhancing drugs are unlikely to be effective in basketball." "71 This backdrop may explain why the NBA's anti-doping policies seem more lax than those of other U.S. sports leagues. However, this is not to say that the NBA's program is actually insufficient or lagging behind the other U.S. sports leagues. WADA has in fact commended the NBA for instituting blood testing for $\mathrm{hGH}$, and the testing program has yielded very few positive results. ${ }^{72}$ Therefore, while the NBA's antidoping policies may not seem as stringent as the WADA Code or even other U.S.

66. NBA Fines \& Suspensions, SPOTRAC, https://perma.cc/BC6Z-DYFH.

67. Dan Devine, Does John Collins's PED Suspension Signal a Larger Change in the NBA?, RINGER (Nov. 5, 2019), https://perma.cc/XP64-VG8J ("[John] Collins intends to appeal the test results, claiming that the offending peptide came from a supplement which, "unbeknownst to me, had been contaminated with an illegal component."'); Zach Kram, Damn, Sun: Deandre Ayton Banned 25 Games for a Positive Test, RINGER (Oct. 24, 2019), https://perma.cc/6A9A-Q2J7 ("[Deandre Ayton] tested positive for a diuretic, [but] ... [f]ollow-up tests of Ayton revealed no traces of other banned substances, and the players' association will try to get the suspension reduced under the CBA's 'unintentional ingestion' provision.").

68. Henry Abbott, WADA: NBA Has Anti-Doping “Gaps,” ESPN (Oct. 18, 2012), https://perma.cc/7MYN-7UKU.

69. Sam Goldaper, NBA Will Ban Drug Users, N.Y. TIMES (Sept. 29, 1983), https://perma.cc/SA4JL6ZW.

70. Haagen, supra note 4, at 841.

71. Abbott, supra note 68. It is unclear whether the assertion that performance-enhancing drugs are less useful in basketball is completely accurate, but it is regularly put forth as a reason for the relatively few positive tests. As noted, "SPEDs sometimes trigger side-effects that would be detrimental for playing basketball. While they may help a player become more muscular and recuperate faster, they can also rob a player of quickness and coordination and make him more susceptible to injury, muscle cramps and dehydration." Michael McCann, Examining Wilson Chandler's Suspension for PEDs and Infrequency of Steroids in the NBA, SPORTS ILlUSTRATED (Aug. 29, 2019), https://perma.cc/NA3C-NYHW.

72. Abbott, supra note 68; WADA Commends Introduction of NBA hGH Blood Testing, WORLD AnTI-DopIng AGENCY (Apr. 17, 2015), https://perma.cc/Q3N4-CFEF; Andrew Keh, NBA To Test Players for H.G.H. Starting Next Season, N.Y. TIMES (Apr. 16, 2015), https://perma.cc/T548-BYSX; McCann, supra note 71. Adam Silver, the commissioner of the NBA, has said: "We may be just that we're fortunate in the NBA that there is a cultural view that those types of drugs are not helpful for performance." Sean Highkin, NBA Commissioner Says the League Doesn't Have a PED Problem, USA TODAY (Mar. 1, 2014), https://perma.cc/CZZ6-JRQX. 
sports leagues, it is not clear that dramatic changes are needed to effectively address doping within the NBA.

\section{The NFL Policy}

The NFL began steroid testing "for informational purposes" in 1987, and started suspending players for steroid use in $1989 .{ }^{73}$ The NFL were early adopters of such testing; for example, the MLB only began testing in $2002,{ }^{74}$ and the NBA only began testing in $1998 .{ }^{75}$ The NFL has long prided itself on having the "most stringent testing policy among the major American sports leagues" and has continued to adapt its policies throughout the years to address performance enhancing drug scandals as they emerge. ${ }^{76}$

The NFL anti-doping policy is contained within the NFL Policy on Performance Enhancing Substances ("NFL Policy"). The NFL testing policy follows a similar testing regime to that of the NBA, but the tests occur with more frequency. ${ }^{77}$ Every player in the NFL will be tested at least once per league year. ${ }^{78}$ Each week during the preseason and regular season, ten players from every team in the NFL will be randomly selected for urine testing. ${ }^{79}$ During the postseason, ten players from every team in the playoffs will be tested each week for as long as that team remains in the postseason. ${ }^{80}$ Much like in the NBA, urine samples may be collected at any time, but the collection of blood specimens is "prohibited on game days unless the player's day off is scheduled for the day following a game day, in which case blood collections may occur following the conclusion of the game." $" 81$ Unless a player is in "reasonable cause testing," $\$ 2$ they will undergo no more than six blood tests in any calendar year. ${ }^{83}$

Each week in the regular season, eight teams are randomly selected, and within each of those teams five of the ten selected players are randomly selected for serum

73. Sam Farmer, Steroids "Rampant" in Old NFL, L.A. TIMES (Mar. 24, 2005), https://perma.cc/MN3L-C7KG.

74. A Timeline of MLB's Drug-Testing Rules, USA TODAY (Mar. 28, 2014), https://perma.cc/27A2-CN89.

75. Janny Hu, Steroid Issue a Layup, So Far / But NBA Could Find Itself in Spotlight Soon, SFGATE (Apr. 10, 2005), https://perma.cc/VSV4-P4A5.

76. Judy Battista, NFL and Union To Strengthen Steroid Testing, N.Y. TIMES (Jan. 25, 2007), https://perma.cc/9UES-A5MB (detailing addition of EPO, a drug common in cycling, as a banned substance); NFL, Players Association Announce Major Changes in Steroids Policy, NFL (Sept. 17, 2014), https://perma.cc/AC6B-8P8V (detailing the implementation of hGH testing).

77. NFL POLICY, supra note 25, at 4-6.

78. Id. at 5. The League Year begins with the opening of free agency and ends with the conclusion of the Super Bowl. 2020 Important NFL Dates, NFL OPERATIONS, https://perma.cc/CW9V-4JZE (last visited Oct. 31, 2020).

79. NFL POLICY, supra note 25, at 5.

80. Id.

81. Id. at 7 .

82. "Any Player testing positive for a Prohibited Substance, including a Player who tested positive or for whom there is sufficient credible evidence of steroid involvement" may be placed into reasonable cause testing. $I d$. at 5 .

83. Id. at 12 . 
blood testing in addition to urine testing. ${ }^{84}$ During the postseason, five of the ten players selected for testing each week will receive serum blood testing in addition to urine testing. ${ }^{85}$ During the offseason, an independent administrator for the NFL will randomly assign ten percent of each team's selected players each week to receive serum blood testing in lieu of urine testing. ${ }^{86}$

Specimen collections generally occur at a team facility, stadium, or scouting combine venue. Upon being notified that they have been selected for testing, a player must submit a specimen within three hours and may not leave the premises for any reason. ${ }^{87}$ If specimen collection is to occur away from one of these facilities, the independent administrator responsible for collecting the specimen may contact the player to notify them that they have been selected and schedule a collection time within twenty-four hours at a site not more than forty-five miles away. ${ }^{88}$ This is an attempt to ensure that players are not aware of when they will be tested, but without having to constantly monitor their daily movements, as the WADA Code seeks to do with its whereabouts testing.

The first time a player violates the NFL Policy, they are suspended without pay pursuant to the following schedule: (1) two regular or postseason games for a positive result for stimulants or diuretics; (2) six regular or postseason games for a positive result for an anabolic agent; or (3) eight regular or postseason games for "the manipulation and/or substitution of a test and the use of a prohibited substance." 89 A second violation for stimulants or diuretics results in a five-game suspension, and a second violation for anabolic steroids results in a sixteen-game suspension. ${ }^{90}$ The third time a player violates the NFL Policy, they will "be banished from the NFL for a period of at least two seasons." 91 Considering the sixteen-game length of an NFL regular season, these punishments can result in a large impact on both the team's success and the player's salary.

Like the WADA Code, the NFL grants TUEs for specific medications that are appropriate for treatment of a corresponding medical conditions. ${ }^{92}$ These exceptions must be granted on the front-end, and will be granted retroactively only "if emergency use of the prohibited substance is necessary to avoid morbidity or mortality of disease or disorder." 93 The NFL also allows a player to present evidence establishing that the presence of the prohibited substance was not due to his fault or

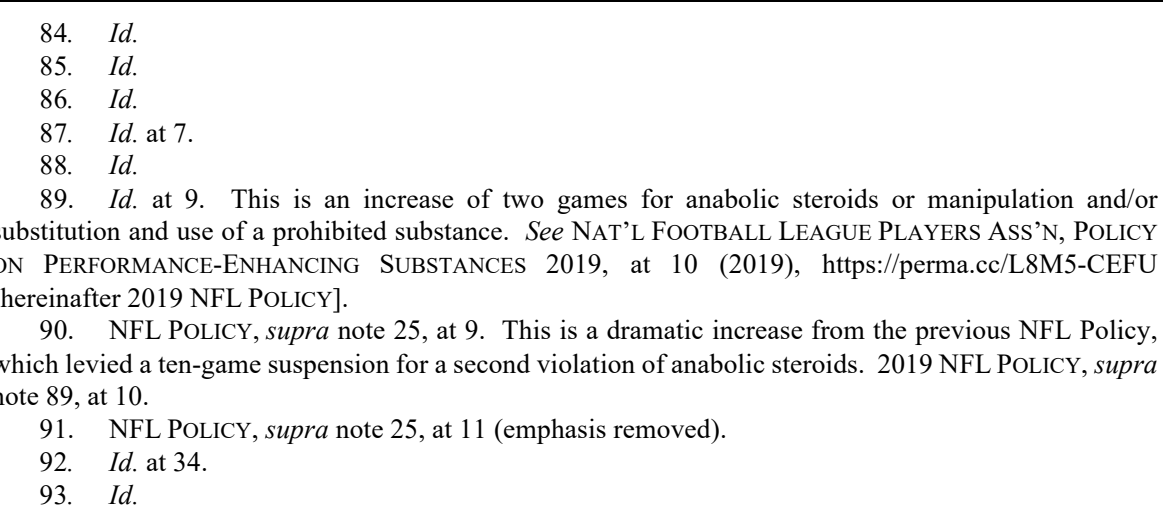


negligence; but otherwise, it does levy punishments to all players found to be in violation of the policy, regardless of the circumstances. ${ }^{94}$

As detailed above, the NFL's policies are stringent and punitive. The NFL has made consistent efforts to close loopholes and address issues to ensure that its antidoping policy remains the most comprehensive in American sports. ${ }^{95}$ The addition of hGH blood testing, the continued dedication to randomized testing throughout the season, and the increases in punishment length demonstrate that the NFL continues to take its anti-doping policies seriously. ${ }^{96}$

\section{The MLB Program}

Though Major League Baseball has a long history with doping, its current antidoping policy can be traced to the BALCO scandal of the early 2000s. In 2002, federal agents began investigating the Bay Area Laboratory Co-Operative (BALCO), a California lab suspected of supplying performance enhancing drugs to MLB players and other athletes. ${ }^{97}$ As the BALCO scandal continued to implicate athletes such as baseball stars Barry Bonds and Jason Giambi, it "forced Major League Baseball to strengthen its steroid-enforcement policy." 98 Facing pressure from Congress to implement stricter steroid policies, MLB began "survey testing" in 2002 to gauge how many players were doping. ${ }^{99}$ Five to seven percent of the players tested positive, and mandatory testing was implemented in 2004. ${ }^{100}$

In 2006, MLB hired former Senate Majority Leader George Mitchell to conduct an investigation into PEDs in the league, which culminated in the Mitchell Report, ${ }^{101}$ a "409-page report that identified more than 85 current and former baseball players." 102 The Mitchell Report also recommended three ways MLB could improve its policies: "(1) by vigorously investigating the use of performance-enhancing drugs through non-analytical evidence, enhancing cooperation with law enforcement authorities, and establishing a department of investigations; (2) by improving the player education program; and (3) by implementing a 'state-of-the-art drug testing

94. Id. at 31

95. Jarrett Bell, Bell: HGH Testing Should Finally Close NFL Loophole, USA TODAY (Sept. 25, 2014), https://perma.cc/K32L-P3Y3 (detailing the addition of hGH blood testing in the NFL); Michael S. Schmidt, Doping Experts Find Loopholes Beyond Baseball, N.Y. TIMES (Dec. 11, 2007), https://perma.cc/524D-BXU7 (stating that NFL players know they will not be tested on game days). The NFL has since mandated that urine testing may occur on any day of the week. NFL POLICY, supra note 25 , at 6 .

96. Bell, supra note 95 .

97. What Is the Balco Scandal?, TELEGRAPH (Mar. 21, 2011), https://perma.cc/8WH8-EJM2.

98. Mark Fainaru-Wada \& Lance Williams, Steroids Scandal / The Balco Legacy / From Children To Pros, the Heat Is on To Stop Use of Performance Enhancers, SFGATE (Dec. 24, 2006), https://perma.cc/N2UA-8BZY.

99. Stiefel III, supra note 10, at 1232.

100. Id.

101. Id. at 1233 .

102. Rhiannon Walker, Ten Years Ago, the Mitchell Report Rocked Major League Baseball, UNDEFEATED (Dec. 13, 2017), https://perma.cc/A86W-YZB7. 
program." "103 The MLB Commissioner subsequently adopted these recommendations and MLB has continued to vigilantly police doping. ${ }^{104}$

The current MLB anti-doping policy can be found in Major League Baseball's Joint Drug Prevention and Treatment Program (the "MLB Program"). Currently, MLB tests every player at least three times a year: Each player is subject to an unannounced urine specimen collection upon reporting to Spring Training, and will be randomly selected for a urine specimen collection once during the season and once during the offseason. ${ }^{105}$ In addition, there are 4,800 urine specimen collections from randomly selected players during each season (at least 200 of which are conducted during Spring Training) and 350 urine specimen collections during each offseason. ${ }^{106}$ Each player will also be randomly selected once for a blood specimen collection during the season to test for hGH (collected post-game, as with the NFL and NBA); in addition to those tests, 500 blood specimen collections of randomly selected players will occur during the season and 400 during the offseason. ${ }^{107}$ A test is considered "positive" for PEDs if: (1) laboratory analysis confirms a substance; (2) a player refuses or, without good cause, fails to take a test; or (3) a player attempts to substitute, dilute, mask, or adulterate a specimen or in any other manner alter a test. $^{108}$

MLB's punishment for a positive test for a PED is as follows: (1) for a first offense, an 80-game suspension; (2) for a second offense, a 162-game/183-days-ofpay suspension; and (3) for a third offense, permanent suspension from Major League and Minor League Baseball, with a chance to apply for discretionary reinstatement after a minimum period of two years. ${ }^{109}$ These punishments constitute at least a large portion of a 162-game MLB season, or potentially more, and are doled out frequently, with four suspensions for PEDs levied in just the first three months of $2020 .^{110}$

Like the NBA and NFL, MLB also allows players to obtain TUEs prior to taking any substance. ${ }^{111}$ It also gives players the opportunity to provide evidence of no significant fault or negligence, but like WADA, and unlike the NFL, it provides explicit limits on how much a punishment can be mitigated. ${ }^{112}$ In the case of no significant fault or negligence, the arbitration panel that hears the evidence may reduce the suspension, subject to the following limitations: (1) The panel may not reduce the penalty for a first-time offense to fewer than thirty games; (2) the panel

\footnotetext{
103. Stiefel III, supra note 10, at 1233-34.

104. Id. at 1234 .

105. MLB PROGRAM, supra note 25, at 15.

106. Id. at 16

107. Id.

108. Id. at 21 .

109. Id. at 37-38.

110. MLB Fines and Suspensions, SPOTRAC, https://perma.cc/QMQ5-TFHP (last visited Oct. 30,

111. MLB PROGRAM, supra note 25, at 22.

112. Id. at 51 .
} 2020). 
may not reduce the penalty for a second-time offense to fewer than sixty games; and (3) the panel may not reduce the penalty for a third-time offense. ${ }^{113}$

Proponents of the WADA Code would argue that the Code is far more effective than U.S. sports leagues at detecting and deterring doping. However, while the NBA, NFL, and MLB policies are not as punitive and do not require testing as frequently as the WADA Code, it is not clear that these polices are actually less effective than the WADA Code at deterring doping. Admittedly, there is some room for improvement to the anti-doping policies of the Big Three, particularly with the issues of conflict of interest and transparency. However, as explored further in Part II, WADA is not the correct solution for these problems.

\section{THE REASONS TO ADOPT THE WADA CODE ARE NOT PERSUASIVE}

When considering whether or not U.S. sports leagues should adopt the WADA Code, it is important to consider all of the drawbacks that would come with its adoption. The WADA Code has harsher requirements and harsher punishments than the U.S. sports leagues' policies, but proponents of the Code argue that its harshness is justified in order to prevent doping. ${ }^{114}$ However, these proponents underappreciate the effects that the Code's harshness has on athletes. The WADA Code implicates serious privacy concerns, and its lengthy minimum punishments are overly punitive, particularly as they also apply to athletes who unintentionally ingest a prohibited substance. As explained in this Part, the arguable benefits of the WADA Code are not worth any of the likely harms that may accompany its implementation.

Additionally, the question of whether the WADA Code is actually more effective than the NBA, NFL, and MLB policies at catching doping violations is difficult to answer because the testing procedures are always playing catch-up with the actual drugs and methods used. ${ }^{115}$ This is best illustrated by looking at famous cases of long-term evasion of punishment, such as Lance Armstrong, ${ }^{116}$ the BALCO

113. Id.

114. Halt, supra note 8, at 278 ("While acknowledging that the requirements place a heavy burden upon athletes, the IAAF believes that the new 'whereabouts' rule strikes a proper balance between the need to locate cheaters and the rights of clean athletes."); Stewart, supra note 10, at 225 ("They see the shift [to the WADA Code] as a necessary evil in maintaining drug-free competition."); Gandert, supra note 7, at 299 ("While some athlete representatives find [the penalties] unfair, the strong penalties are an asset of the system, helping to keep cheaters out and providing strong disincentives to cheat."); Haagen, supra note 4, at 846 ("The WADA Code explicitly makes a series of trade-offs in determining how to combat performance-enhancingdrugs [sic], and those trade-offs place heavy burdens on participating athletes.").

115. Saroja Cuffey, Note, Passing the Baton: The Effect of the International Olympic Committee's Weak Anti-Doping Laws in Dealing with the 2016 Russian Olympic Team, 43 BROOK. J. INT'L L. 665, 665 (2018) ("With greater advancements in detecting performance-enhancing drugs (PEDs), however, come more creative methods and advancements in undetectable PEDs.").

116. Alexandra M. Franco, Attaining Olympus: A Critical Analysis of Performance-Enhancing Drug Law and Policy for the 21st Century, 28 S. CAL. INTERDISC. L.J. 1, 24 (2018) (noting that Don Catlin, founder of WADA-approved UCLA Olympic laboratory, "tested Lance Armstrong approximately fifty times, and Armstrong never once tested positive for doping"). 
scandal, ${ }^{117}$ and the state-sponsored Russian doping conspiracy. ${ }^{118}$ The fact that new drugs are constantly being introduced and new procedures are being designed to fool drug tests means that "[w] here doping is concerned, the arms race has outrun the cold war."119 So, in order to properly justify U.S. sports leagues adopting the harsher policy embodied in the WADA Code, it should, at the very least, be proven to be a dramatically more effective regime.

\section{A. Whereabouts Testing and Long Minimum Punishments Are Overly InVASIVE AND PUNitive}

As noted above, the WADA Code requires whereabouts testing and strict minimum punishments, and the invasiveness and punitiveness of these policies are strong reasons for the Big Three to decline to follow that regime. The WADA Code mandates that every athlete subject to whereabouts testing provide "one specific 60minute time slot where he/she will be available at a specific location" every day, seven days a week, 365 days a year. ${ }^{120}$ While athletes subject to the WADA Code have largely come to tolerate whereabouts testing out of necessity, the testing remains unnecessarily restrictive and has major privacy implications for athletes. It has been criticized as "effectively turn[ing] athletes into prisoners" 121 and as being unnecessarily opaque in its procedures. ${ }^{122}$ Considering the collective bargaining that currently underlies the Big Three's policies, it is extremely unlikely that any of the players' unions would agree to such invasive practices. ${ }^{123}$

117. Sydney Lupkin, Why Drug Tests Can't Catch Doping Athletes, ABC News (Aug. 6, 2013), https://perma.cc/FA6A-NRFW ("Trevor Graham, who coached track and field athletes for the Olympics, anonymously turned in a dirty syringe to the USADA, revealing that athletes were getting a then-unknown drug from the Bay Area Laboratory Co-operative.").

118. Cuffey, supra note 115, at 666 ("WADA identified Grigory Rodchenkov, the director of Russia's anti-doping laboratory, as a major actor in the doping cover-up. Rodchenkov would later admit to developing a three-drug mixture of banned substances that he provided to dozens of Russian athletes, replacing thousands of PED contaminated urine samples and passing these samples through a circular hole cut through the wall, concealed by a cabinet during the day."); Gandert, supra note 7, at 309 ("According to these allegations, over one thousand Olympic and Paralympic athletes participating in thirty sports benefitted from the Russian cheating conspiracy, which dated back to 2011." The allegations were first publicized in December 2014).

119. A.A.K., Why Doping in Sport Is So Hard To Catch, ECONOMIST (Nov. 26, 2015), https://perma.cc/AV6G-E3TJ.

120. WADA CODE, TESTING \& INVESTIGATIONS, supra note 47 , at 76. :

121. Halt, supra note 8, at 287.

122. See, e.g., Laura Wagner, An Anti-Doping Agent Occupied Serena Williams's Property and Everyone Is Being Squirrelly About It, DEADSPIN (June 27, 2018) https://deadspin.com/an-anti-dopingagent-occupied-serena-williams-s-propert-1826993294 (noting that Serena Williams has been tested far more often than comparable players, to the point that Williams's team considered it "invasive," and that the U.S. Anti-Doping Agency offered no explanation other than "that they are allowed to send agents to test her wherever and whenever they want, for whatever reason they want").

123. Back in 2003, an NBA Players Association spokesperson stated that the union was displeased that NBA athletes participating in the Olympics may be subject to whereabouts tracking and surprise testing. Amy Shipley, Olympic Policy Concerns NBA Players, WASH. Post (Mar. 7, 2003), https://perma.cc/UL5V-XL55. 
Additionally, the long minimum sanctions under the WADA Code are overly punitive and fail to take into account other deterrent factors. The two-year minimum suspension, along with WADA's strict liability policy, puts immense pressure on athletes to closely scrutinize everything they ingest on the off chance that they may accidentally ingest a prohibited substance. Considering the fact that many of the prohibited substances on the list may not actually have any performance-enhancing effects, this is much more daunting than it may seem. ${ }^{124}$ Additionally, these lengthy punishments do not take into consideration other factors that may deter doping, such as loss of sponsorships, reputational damage, and increased fines, which are discussed further in Part III. WADA takes an approach that seems to be based on the idea that the length of a suspension is the only factor that can properly deter athletes from doping, whereas, in reality, there are many other factors to consider. Despite any concerns one might have with the Big Three's anti-doping policies, these drawbacks alone would lead to dramatic changes to their current regimes and are unlikely to be tolerated by any players' union.

\section{B. The Number of Documented Violations Under Each Policy Are NOT DRAMATICALly DifFERENT}

Indeed, even if the drawbacks to the Code were justified by the promise of more effective doping prevention, the Code should at least be demonstrably more effective than the Big Three's policies at catching athletes who dope. To know how effective each drug testing policy is, one would have to know the number of athletes that are actually doping and how many of those are actually caught. This would allow for a true empirical comparison of the effectiveness of each policy. However, this data does not exist. In the absence of empirical data, it is instead worth looking at the number of doping violations from WADA and from the major U.S. sports leagues to see whether there is a dramatic difference in violation rates that would suggest increased effectiveness. This comparison is an imperfect one and does not tell the entire story, but that is precisely the point. These numbers cannot give us any true indication of effectiveness - a fact that renders any assertion that the Code is more effective somewhat toothless. Nevertheless, it is worth looking at some of the available numbers to note the lack of any dramatic disparity between athletes caught doping under the Code and the Big Three's regimes.

The most recent data available from WADA is from 2017, when 245,232 samples were collected by anti-doping organizations and analyzed by WADA-accredited laboratories. ${ }^{125}$ Of those samples, 1,459 were confirmed to be anti-doping rule violations ("ADRVs"). ${ }^{126}$ This does not include the samples that were found to have adverse analytical findings, ${ }^{127}$ but only those samples that ended up as a violation for

124. See generally Jules A.A.C. Heuberger \& Adam F. Cohen, Review of WADA Prohibited Substances: Limited Evidence for Performance-Enhancing Effects, 49 SPORTS MED. 525 (2019).

125. ADRVS REPORT, supra note 37, at 6.

126. Id.

127. The WADA Code defines "Adverse Analytical Finding" ("AAF") as: A report from a WADA laboratory that "establishes in a Sample the presence of a Prohibited Substance or its Metabolites or 
an athlete. ${ }^{128}$ This means that about $0.6 \%$ of the collected samples ended up indicating a rule violation that led to punishment.

In 2019, the NFL reported 22 violations of their policy on performance enhancing substances. ${ }^{129}$ The NFL conducts around 15,000 tests for prohibited substances per year. $^{130}$ This equates to about $0.15 \%$ of samples indicating a prohibited substance violation. The NFL also tests for substances of abuse, ${ }^{131}$ of which there have been 20 violations this season. ${ }^{132}$ Assuming that violations for substances of abuse count as a violation for a prohibited substance, even though they are not performance enhancing, that would mean about $0.3 \%$ of samples contained a prohibited substance.

MLB had six violations of their PED policy in the 2019 season. ${ }^{133}$ In the 2019 season, MLB administered 11,619 tests. ${ }^{134}$ This means about $0.06 \%$ of the tests came back as a violation meriting punishment.

Finally, in 2019, the NBA found four violations of their policies related to PEDs. ${ }^{135}$ Per the NBA-NBPA Collective Bargaining Agreement, the NBA agrees to conduct no more than 1,525 total tests during the season and no more than 600 total tests during the offseason, for a total of up to 2,125 tests per year. ${ }^{136}$ This equates to about $0.19 \%$ of samples coming back positive and meriting punishment. The NBA historically has not had many PED violations, having only fourteen total suspensions for PEDs, including the latest four suspensions. ${ }^{137}$ In fact, in the history of the league, before the 2019 season, "no more than two players have ever tested positive in the same season."138 Though it is not possible to know the underlying reason for the low number of violations, this could indicate that the NBA is becoming more vigilant in pursuing their anti-drug policies, or it could mean that only a few athletes

Markers or evidence of the Use of a Prohibited Method." WADA CODE, supra note 6, at 88. An AAF does not become an ADRV if there is a valid TUE, the athlete is exonerated, there is no case to answer (departure from testing standards, case outside of WADA's jurisdiction, etc.), or the case is pending. ADRVS REPORT, supra note 37, at 6.

128. ADRVS REPORT, supra note 37 , at 6.

129. NFL Fines \& Suspensions, SPOTRAC, https://perma.cc/TBN5-UMH4 (last visited Oct. 27, 2020).

130. Reed Albergotti, Is the NFL Telegraphing Drug Tests?, WaLl ST. J. (Jan. 20, 2011), https://perma.ce/EBE7-4KTA.

131. The NFL prohibits the "illegal use of drugs and the abuse of prescription drugs, over-thecounter drugs, and alcohol (hereinafter 'Substances of Abuse')." NAT'L FOOTBALL LEAGUE, POLICY AND PROGRAM ON SUBSTANCES OF ABUSE 2020, at 1 (2020), https://perma.cc/2RZ2-9744.

132. NFL Fines \& Suspensions, supra note 134.

133. Steroid Suspensions in Major League Baseball, BASEBALl AlmANAC, https://perma.cc/TJ2EU8DL (last visited Jan. 4, 2021).

134. Ronald Blum, MLB Drug Tests Drop Sharply During Coronavirus Pandemic, Associated PRESS (Dec. 1, 2020), https://apnews.com/article/mlb-baseball-coronavirus-pandemic-doping196b9320861470f882d3554b24fed5c7 (noting that the MLB collected "9,332 urine samples and 2,287 blood samples in the year ending with the 2019 World Series"). This Note does not use data from the shortened 2020 season because of changes made due to the COVID-19 pandemic.

135. NBA Fines \& Suspensions 2019-2020 Season, SPOTRAC, https://perma.cc/KGS9-48ZA.

136. NBA AGREEMENT, supra note 38 , at 433.

137. Matt Ellentuck, The NBA's Rise in PED Suspensions, Explained, SB NATION (Nov. 5, 2019), https://www.sbnation.com/nba/2019/11/5/20949723/nba-ped-suspensions-deandre-ayton-wilsonchandler-john-collins-steroids-banned-substances.

138. Id. 
decided to try doping this year and were subsequently caught. ${ }^{139}$ On the other hand, the NBA tests much less frequently than the other two major sports leagues, and this may be the reason for the low number of PED violations it has uncovered. Though hard conclusions are difficult to draw, what we can know from the evidence is that, of all the tests conducted in 2019 season, only four violations were reported.

Again, based on these numbers, it is difficult to ascertain whether one is any more effective than the other. ${ }^{140}$ WADA has a higher percentage of anti-doping rule violations discovered, but WADA also covers a much larger number of athletes. To try to make the comparison more analogous to the U.S. leagues, one option is to compare the WADA violations for each sport to the U.S. sports leagues' violations. For international games of American football, ${ }^{141}$ WADA took 622 samples and had 13 ADRVs (2.1\%); for baseball, WADA took 1,039 samples and had 8 ADRVs (0.8\%); for basketball, WADA took 5,697 samples and had 24 ADRVs $(0.4 \%) .{ }^{142}$ These numbers indicate that there are certainly more violations caught by WADA, but the numbers do not present a violations rate appreciably different than the U.S. leagues, and certainly nothing in the data affirmatively indicates widespread doping in U.S. leagues. In fact, some of the basketball samples taken are likely from U.S athletes participating in the Olympics or international competitions, and there were no violations by U.S. athletes, which may indicate that the NBA's current policies are working to deter PED use among players.

It is quite difficult to draw any clean conclusions about effectiveness from the data that is available, but assuming that these various data sets are analogous enough to allow for comparison, the data we have conflicts with the idea that WADA is objectively more effective at discovering doping violations than U.S. sports leagues. ${ }^{143}$ If the percentage of violations caught under the WADA Code were drastically different, perhaps that would indicate the increased effectiveness of the WADA Code, but the differences are simply not that appreciable. Additionally, there

139. It should be noted that " $[\mathrm{t}] \mathrm{hree}$ players getting popped in three months is, in the words of NBA executive turned ESPN analyst Bobby Marks, “unprecedented."' Devine, supra note 67. It is unclear whether this will be an ongoing trend, as "[m]aybe the NBA's testing has improved [or] maybe a few more players than normal have been trying to gain an edge, and are paying the price for it." $I d$. Only time will tell. However, before the NBA season was suspended due to COVID-19, no other players had tested positive for SPEDs in the 2019-20 season. NBA Fines \& Suspensions 2019-2020 Season, supra note 140.

140. Complaints regarding the U.S. sports leagues' anti-doping policies largely boil down to not enough monitoring and needing to collectively bargain to add prohibited substances. However, these claims of ineffectiveness are impossible to prove objectively because one cannot know the percentage of total violations caught. It should be noted that most of the major doping scandals were not discovered by testing, but instead by whistleblowers or criminal investigations. Haagen, supra note 4, at 846 ("WADA is not definitively more effective in ridding sport of performance-enhancingdrugs [sic], which warrants a serious debate about whether the costs associated with this program are worthwhile in the context of American professional sports.").

141. "The International Federation of American Football (IFAF) is the international governing body for the sport of American football and is responsible for all regulatory, competition, performance and development aspects of the game on a global level." The IFAF is a WADA Code signatory. About, INT'L FED'N OF AM. FOOTBALL, https://perma.cc/3NS4-WWPN (last visited Oct. 28, 2020).

142. ADRVS REPORT, supra note 37, at 10.

143. Gandert \& Ronisky, supra note 12, at 841 ("WADA currently has stricter and more effective anti-doping policies than the NFL."). 
is the argument that an effective policy would find that there are almost no violations. As former Congressman Henry Waxman noted in 2005, "the percentage of NFL players who test positive for steroids is very low... Is this because the policy is working, or is this because players have figured out how to avoid detection?"144 This gets to the core of why it is so difficult to assess the effectiveness of the various policies, because it is unclear whether a perfect policy would catch more offenders or catch none.

Essentially, without knowing exactly how many athletes are actually doping, it is impossible to determine the effectiveness of the differing polices, because there is no way to compare the percentage of doping athletes being caught under each regime. What we are able to see from the data is that the violation percentages are not dramatically different, and while this may indicate the effectiveness of the current U.S. league policies, it could just as easily indicate that athletes under these policies are able to escape detection at higher rates. While it is always helpful to consider the data that is available, in the end, the high uncertainty surrounding the reported violation rates under each policy makes this type of data comparison a poor way to assess the overall effectiveness of anti-doping policies in the U.S. sports leagues.

The current controversy over TUEs illustrates this point well. The current view that some critics hold is that TUEs provide a Code-approved method of engaging in doping. Perhaps this is an indictment of the WADA Code, a loophole in what is considered the gold standard, but at a minimum, it goes to show that regardless of how unimpeachable an anti-doping regime may seem, there will always be criticisms that athletes are skirting the rules. Ultimately, if there is any justification for the adoption of the WADA Code in U.S. sports leagues - as WADA proponents argue there is - it cannot be made based on claims of "effectiveness" that cannot be proven empirically. Thus, if such a justification exists, the argument for that justification must be based on other factors than the reported data on PED policy violations.

\section{The Justifications for Stronger Doping Regulations ANd Their FLAWS}

Perhaps the question we should be asking is: Do we find the specter of sports doping so unacceptable that Americans would accept athletes being constantly monitored and harshly punished in exchange for a "level" playing field? ${ }^{145}$ The common justifications put forth for stronger policies like the WADA Code are that weak doping regulations affect fan interest, that doping creates an unfair playing field, and that performance enhancing drugs harm athletes' health. ${ }^{146}$ However, as discussed in this Section, although these justifications do help illuminate ways in which U.S. sports leagues could address concerns about their anti-doping policies, these justifications do not warrant the adoption of the WADA Code in particular.

144. Mark Maske \& Leonard Shapiro, NFL's Steroid Policy Gets Kudos on Capitol Hill, WASH. POST (Apr. 28, 2005), https://perma.cc/8JSL-LUWP.

145. Haagen, supra note 4, at 846 ("Those costs [of the WADA Code] are not speculative, they are real. They include invasions of privacy and false positives.").

146. Hard, supra note 7, at 545 . 


\section{Fan Interest}

As Professors Preston and Szymanski have said, one of the primary reasons given for doping regulation is that doping undermines interest in the sport and damages a sport's reputation. ${ }^{147}$ However, there is research that suggests that violations of doping regulations actually do not have a significant impact on fan interest. ${ }^{148}$ In fact, in the case of MLB, one study found that the announcement of a PED violation does have an initial home game attendance reduction of $8 \%$, but this reduction "fades quickly to the point of being statistically insignificant 12 days after [the] announcement"; and it has only a small negative impact on the game attendance of other MLB teams. ${ }^{149}$ This finding conflicts with the popular assumption that the MLB's well-publicized doping scandals negatively affected viewership, as well as the contention by certain baseball purists that steroids ruined the game or completely negate certain players' stats. ${ }^{150}$ Despite Barry Bonds's steroid use, which was suspected long before he was caught, fans still regularly reminisce about his dominance of the game and how exciting he was to watch. ${ }^{151}$ Mark Johnson, author of a book about the history of sports doping, noted that "Major League Baseball fans' attitudes to doping in sport might be equivalent to how a Rolling Stones fan does not judge Keith Richards for his fondness for drugs .... He delivers an astonishingly great entertainment product that moves people, so fans don't hold him to account for the substances he takes." ${ }^{52}$ This doping ambivalence isn't limited to just MLB; on the contrary, "[t]he more interested people [are] in sports, the more liberal . . . their attitudes towards doping." 153

147. Ian Preston \& Stefan Szymanski, Cheating in Contests, 19 OXFORD Rev. ECON. POL'Y 612, $616(2003)$.

148. See generally Jeffrey Cisyk \& Pascal Courty, Do Fans Care About Compliance To Doping Regulations in Sports? The Impact of PED Suspension in Baseball

, 18 J. SPORTS ECON. 323 (2015).

149. Id. at $341-42$.

150. Ross Newhan, a longtime Los Angeles baseball writer, said about excluding Barry Bonds and Roger Clemens from the Hall of Fame: "Do I feel badly about this given their Hall of Fame-worthy performances before what we call the steroid era? No, I think they took those Hall of Fame-worthy performances and cheapened them to such an extent it is impossible to ignore and was totally unnecessary." Jeff Passan, Why Barry Bonds and Roger Clemens Aren't Getting into the Hall of Fame, ESPN (Jan. 22, 2019), https://perma.cc/3RDF-9WYW. FiveThirtyEight ran a poll asking Americans how they felt about the stats of baseball players who used steroids and found that the "vast majority of peopleeven baseball fans - are not comfortable with just letting the records stand." Roundtable: All of Baseball History Should Get an Asterisk, FIVETHIRTYEIGHT (July 27, 2015), https://perma.cc/4DV4-FCK2.

151. See, e.g., Matt Snyder, Whether You Think He Belongs in the Hall of Fame or Not, Barry Bonds' Numbers Are Fun, CBS SPORTS (Jan. 22, 2018, 9:02 AM), https://perma.cc/5S3A-NGJK; Jason Diamond, How Barry Bonds Made His Case for Greatness 15 Summers Ago, Rolling Stone (July 21, 2016), https://www.rollingstone.com/culture/culture-sports/how-barry-bonds-made-his-case-for-greatness-15summers-ago-94268/ ("And whether you care about how he did it or not, Barry Bonds remains the greatest home run hitter in the history of the game, which means, when fans really needed it the most, Bonds was constantly the most exciting thing about baseball.").

152. Andrew Thurston, Doping in Sports, B.U. ARTS \& SCIS. MAG., Spring 2017, https://perma.cc/XM8C-HE4S.

153. Harry Arne Solberg, Dag Vidar Hanstad \& Thor Atle Thøring, Doping in Elite Sport-Do the Fans Care? Public Opinion on the Consequences of Doping Scandals, 11 INT'L J. SPORTS MKTG. \& SPONSORSHIP 185, 196 (2010). 
These studies and articles from commentators illustrate that despite popular belief, fans will not withdraw their support if doping is not eliminated in sports. Because it doesn't seem as though doping has a significant negative effect on fan interaction in the first place, ${ }^{154}$ it seems unlikely that more strictly regulating doping in sports by adopting the WADA Code would help maintain viewership, attendance, or fan interest. If few people are tuning out because of the prevalence of doping, then the argument that strictly regulating doping would bring back fans who stopped watching because of doping is irrational. Thus, the increase in regulation and stricter punishments for a violation seem unlikely to improve the viewing experience or offer significant benefit to the general viewing public, or even the most invested sports fans. $^{155}$

Considering the decidedly negative feedback the WADA Code whereabouts testing has received from elite athletes, ${ }^{156}$ the increased negative publicity the NBA, the NFL, and MLB would receive from athletes opposing these policies would be overwhelming. Players are used to having some degree of control over doping regulations through their players' unions, and '[t]here are substantial differences in how drug testing policies can be implemented in sports that are subject to collective bargaining and those that are not." 157 In fact, the regulations would actually be more likely to have a negative effect on fan interest, as athletes would be prone to air out their displeasures; and if a star athlete was suspended, a minimum suspension of two years would almost certainly be enough to make at least some fans lose interest. As a New York Times article aptly put it: "The pull of the home team is much stronger than indignation over a scourge that we don't truly comprehend. Fan sensibilities have not been offended as much as they've been anesthetized."158

It is worth noting that cycling saw a dip in its popularity (measured by Tour de France viewership) in 2018, ${ }^{159}$ which, at first glance, could be argued was due to the pervasive doping during Lance Armstrong's record-setting Tour de France run. ${ }^{160}$ However, it also could be due to the simple fact that TV audiences may be shrinking across all sports. ${ }^{161}$ Additionally, Lance Armstrong was a star during that era, and

154. Cisyk \& Courty, supra note 148.

155. One study found that the more interested people were in sports, the less likely they were to agree with the idea that TV stations should stop broadcasting events that had repeated doping exposure. This is perhaps due to the fact that "the desire to watch sport was stronger than the reluctance toward doping." Solberg et al., supra note 153, at 196.

156. See Juliet Macur, Rule Requiring Drug Testers To Know Athletes' Whereabouts Draws Protest, N.Y. TIMES (Mar. 22, 2009), https://perma.cc/G2LJ-GLWU; Stephen Wilson, WADA Willing To Listen on Drug-Testing Complaints, USA TODAY (Feb. 17, 2009), https://perma.cc/42DA-GMHD (stating that tennis superstar Rafael Nadal "said players feel they are being treated like 'criminals"”).

157. Stiefel III, supra note 10 , at 1279 .

158. William C. Rhoden, Fans Tolerate Doping, and Media Remain Fixated, N.Y. TIMES (May 26, 2007), https://perma.cc/LK55-R3RH.

159. Andrew Hood, Is the Tour de France in Trouble?, VELONEWS (Oct. 19, 2018), https://perma.cc/HPA7-JXKG.

160. See Michael Powell, Doping Cloud Still Looms over a Thrilling Tour de France, N.Y. TIMES (July 26, 2019), https://perma.cc/WM6G-2RUA.

161. See Brian Goff, Long-Term Viewership Trends Show Warnings for NFL, NBA and Other Major Sports, FoRBES, (Dec. 16, 2019), https://perma.cc/7VSF-3J83. 
whether he was beloved or hated, it's clear that his notoriety drew in viewership, whereas the Tour's current lack of a star as famous as Armstrong could be hindering its viewership. ${ }^{162}$ Either way, even if the reputation of cycling has been permanently tarnished, "[t]he Tour ... remains a cash cow and is a major driver of the estimated 45 million euros per year in profits for ownership company ASO." ${ }^{63}$ Higher ratings did bounce back for the Tour in 2019 as well. ${ }^{164}$ So, despite the fact that there are reports that doping in cycling remains a pervasive issue, the Tour continues to generate profits, and its TV viewership is not definitively linked to the doping scandals. ${ }^{165}$ As noted by sports ethicist Jan Boxill, "human beings hold contradictory views. They're outraged at Barry Bonds, yet they want to see home runs."166 Ultimately, this contradiction makes it fair to conclude that fan interest does not justify increased doping regulation and the implementation of the WADA Code.

\section{Establishing a Level Playing Field and "Spirit of Sport"}

There is also the issue of fairness in sports, which on its face is a defensible justification for increasing doping regulation in general and adopting the WADA Code as a means to effectuate that goal. However, proponents of this argument overlook the fact that unfairness is baked into every aspect of professional sport. These proponents fail to explain why there is no real push to ensure a level playing field in any aspect of the game outside of doping. It is unclear why doping is treated differently than other enhancements. ${ }^{167}$ In baseball, there are a number of teams that regularly outspend their competitors, but that is seen as just one of the benefits of being a large market team. ${ }^{168}$ Similarly, in football, at the collegiate level there are clear advantages that come with being a well-known Division 1 football team. These advantages end up affecting their athletes' level of play, but this is not seen as much of a concern. ${ }^{169}$ Fans tolerate inequalities of nature, such as Michael Phelps' body

162. A dip in viewership of the Tour de France occurred when Armstrong first retired in 2006. See Doreen Carvajal, Tour's TV Ratings Suffer Sans Armstrong, N.Y. TIMES (July 21, 2006), https://perma.cc/75LD-66KF; Hood, supra note 159 ("Another metric, though harder to measure, is star power. Lance Armstrong might have once been the most hated man in France . . . but he drew in crowds.”). 163. Id.

164. Press Release, NBC Sports, NBC Sports' Live Coverage of Closely Contested Tour de France Concludes This Week \& Weekend Across NBC Sports, July 23, 2019, https://perma.cc/2SHM-H853 ("Viewership for Live Tour de France Coverage Best Since 2015 and UP 11\% from 2018").

165. Matt Slater, Doping Culture in Cycling "Still Exists" According To Circ Report, BBC SPORT (Mar. 8, 2015), https://perma.cc/QB8L-UK6V.

166. Liz Clarke, Lance Armstrong "Deserves To Be Forgotten in Cycling," Federation President Says, WASH. POST (Oct. 22, 2012), https://perma.ce/UJ5B-Y2JB.

167. See Franco, supra note 116, at 7 ("[E]ven when drawing an arbitrary line of enhancement-as anything that enables a person to supersede his or her average, natural capabilities - it is hard to understand why some behaviors are considered enhancing and some are not.").

168. See Bob Nightengale, Players' Criticism in Offseason Spending Validated by Disparity in 2019 MLB Payrolls, USA TODAY (Mar. 26, 2019), https://perma.cc/K9MN-YBE8.

169. See Tom FitzGerald \& Rusty Simmons, A Mismatch for Money, S.F. Chron. (Sept. 11, 2018), https://perma.cc/Q94K-M2FC. 
being uniquely adapted to swimming, ${ }^{170}$ and inequalities of opportunity, such as being from a rich country with the resources to obtain legal performance enhancing methods, yet some fans claim to draw the line at certain performance enhancing drugs and methods. ${ }^{171}$ Yes, sports should ideally have a completely level playing field, but as shown above, it is essentially impossible to create such an environment. So, why is doping treated differently? ${ }^{172}$

One argument is that this difference can trace its roots back to the fan interest justification and the idea that organizations want to secure fair competition because fans are not interested in seeing unfair competition caused by doping. However, because it seems as though doping violations have a difficult to quantify (but likely insignificant) effect on fan interest, this justification for strict doping regulations boils down to maintaining the "spirit of sport." 173 WADA defines the spirit of sport as: "Ethics, fair play and honesty, health, excellence in performance, character and education, fun and joy, teamwork, dedication and commitment, respect for rules and laws, respect for self and other participants, courage, and community and solidarity." 174 This definition has been characterized as "a collection of undefined terms associated with moral norms" and criticized as problematic for "amount[ing] only to the forced introduction of private moral values into an important area of public activity."175 Furthermore, the invocation of the "spirit of sport" is selective; WADA's proponents are not equally as concerned with mitigating unfairness in its many other forms, including team-to-team spending disparities, athletes' economic disadvantages, and inequitable access to technology. It seems fair to say that the ambiguity associated with the "spirit of sport" renders it a somewhat weak justification for the constant monitoring of elite athletes or the extremely strict sanctions that come with a violation.

\section{Protecting Player Health}

Finally, perhaps the best justification for the adoption of the WADA Code as a way to more effectively regulate doping in U.S. sports leagues is maintaining player health. It is important to note first that there are a number of competitive sports actively detrimental to athlete health that remain incredibly popular. Studies link

170. See Valerie Siebert, Michael Phelps: The Man Who Was Built To Be a Swimmer, TELEgRAPH (Apr. 25, 2014), https://perma.cc/GD9E-W8RV.

171. See Hard, supra note 7, at 548 .

172. See id. at 545-46 ("With regard to exogenous advancement, we have a high tolerance for enhancement, no matter how much the sport is changed; we tolerate increasingly sophisticated running spikes, graphite tennis rackets that makes games shorter, and fiber-glass pole vaults to reach new heights. We also tolerate a degree of enhancement to our bodies, such as laser eye surgery, medleys of concentrated and engineered vitamins, and altitude training.").

173. M.J. McNamee, The Spirit of Sport and Anti-Doping Policy: An Ideal Worth Fighting for, WORLD ANTI-DOPING AGENCY (Feb. 21, 2013), https://perma.cc/47DX-HHFT.

174. Hard, supra note 7, at 546 .

175. Franco, supra note 116, at 19; Eoin Carolan, The New WADA Code and the Search for a Policy Justification for Anti-Doping Rules, 16 SETON HALL J. SPORTS \& ENT. L. 1, 19 (2006). 
football with an increased risk of long-term neurological conditions, ${ }^{176}$ yet football remains the most popular sport in America. ${ }^{177}$ Rugby leads to a number of specific physical injuries as well, ${ }^{178}$ but it remains a popular sport worldwide. ${ }^{179}$ This is not to say that fans don't care about player health at all, but it is clear that this concern is selectively invoked. The health of athletes can be raised as a concern against doping, but "fans can be outraged that football has left some former players with severe brain trauma yet still slip on their favorite team's jersey and watch 'Monday Night Football.' With entertainment, fans don't often let morality ruin their fun." ${ }^{\text {"180 }}$

Nevertheless, the "reality of modern high performance is that athletes make choices about, and give consent to, high risk decisions oriented towards driving their bodies to the limits of physical capacity" and athletes may choose to play football, but may not want to be forced to add risk by using PEDs. ${ }^{181}$ Thus, if the rationale for regulating doping is truly to support player health and mitigate any additional health risks, then that should be the primary goal of the regulations. Without a doubt, there are PEDs that are detrimental to player health, but there are also a number of banned substances that do not have harmful effects and may barely even affect performance. ${ }^{182}$ One suggestion for a better approach is to consider the adoption of "a simplified matrix [that] may consider prohibiting drugs/methods likely to increase social and individual harms (e.g. strongly performance-enhancing/performanceenhancing and potentially health-damaging drugs) in a specific sport."183 This method would make it so that a substance would never be included on the prohibited list solely because it is misused, but only if there is scientific evidence available that it "potentially significantly enhances performance and at the same time may possess a health risk for athletes." 184 This would mean that the WADA Code would no longer solely consider whether "taking [a] drug goes against the spirit of sport," but would adopt a scheme that better prioritized scientific testing to see if the drug really does pose significant health risks to athletes and also enhance performance. ${ }^{185}$ If

176. See generally Jesse Mez et al., Clinicopathological Evaluation of Chronic Traumatic Encephalopathy in Players of American Football, 318 JAMA 360 (2017).

177. Jim Norman, Football Still Americans' Favorite Sport To Watch, GALluP (Jan. 4, 2018), https://perma.cc/S8PA-CBLH.

178. Chris Bodenner, Which Is More Dangerous, Rugby or Football?, ATLANTIC (Oct. 14, 2016), https://perma.cc/AGE4-CCTF.

179. World Rugby's Minnows Show the Huge Leaps in Fandom, NIELSEN SPORTS (Sept. 24, 2015), https://perma.cc/978N-KVBQ.

180. Juliet Macur, Doping Won't Deter Olympics' Viewers. Just Watch., N.Y. Times (May 19, 2016), https://perma.cc/8A7Q-LRN8.

181. Hard, supra note 7, at 549

182. Id. at 546 ("[S]ome anabolics are banned from all sports even though there would be no performance enhancement. WADA's reasoning rests on the existence of a 'sportsman' ideal: 'The premise ... is that there are certain basic doping agents which anyone who chooses to call himself or herself an Athlete should not take."').

183. Marie Overbye, An (Un)desirable Trade of Harms? How Elite Athletes Might React To Medically Supervised "Doping" " and Their Considerations of Side-effects in This Situation, 55 InT'L J. DRUG POL'Y 14, 26 (2018).

184. Id. at 27 .

185. WADA's science director, Olivier Rabin, noted that "[a] few studies in the scientific literature also showed that meldonium [a newly banned substance] had a potential performance-enhancing benefit." 
implemented, this would ensure that the doping regulations really are designed to protect athletes, rather than just a list of substances that may or may not affect performance or player health. There is the claim that this would disadvantage athletes who were unwilling to take PEDs, even if there is no scientific evidence of harm. But the current regime permits variations in training schedules and certain athletes choose to engage in legal performance enhancing practices that other athletes do not. ${ }^{186}$ There is a forceful argument that the regulations should not get into policing what every athlete is willing to do, but should only address the health of athletes. This would prove that the driving motivation behind the regulations truly is for the benefit of the players, as opposed to vague notions of the "spirit of sport."

Yet, concerns over player health still does not justify the WADA Code's whereabouts testing or the mandatory minimum of a two-year suspension. While the goal of improving player health is important, a sport's anti-doping policies should be testing to make sure that athletes are not taking substances that could harm their health. It should not rise to the level of constant policing and invasive testing, as the WADA Code requires. Currently, athletes are willing to take immense risks in order to better their performance and increase their chances at excelling in competition. In a 1980's study, researcher Bob Goldman asked top performing athletes "whether they would take a drug that guaranteed them a gold medal but would also kill them within five years. More than half of the athletes said yes. When he repeated the survey biannually for the next decade, the results were always the same. About half of the athletes were quite ready to take the bargain." 187

If the athletes are this dedicated to finding a substance that can improve their chances at winning, even at the expense of their health, it seems likely that only a system that monitors athletes 24/7 would deter them, and even WADA's "whereabouts" testing does not rise to this level of invasiveness. Such a policy is undesirable for the reasons explored earlier in this Note, and over-policing to catch doping would perhaps be effective but would also necessitate even further intrusions into athlete privacy. In addition to a system that monitors for and bans only healthadverse drugs, an education program that alerts athletes to exactly why certain drugs are banned and the health risks that come with them-rather than just generally opining on the dangers of PEDs or painting in broad strokes as the current WADA education program does - may be more effective. ${ }^{188}$ There may be some athletes who still choose to take the drugs that carry immense health risks, but even constant policing and the strictest sanctions are unlikely to properly prevent this. Athlete health is incredibly important, but so is respecting their right to privacy and autonomy. Constant policing to ensure athlete health unnecessarily infantilizes and

Carolyn Beans, What Does It Take To Get a Drug Banned for Enhancing Athletes' Performance?, NPR (June 14, 2016), https://perma.cc/W5SY-4V86. Perhaps more studies should be done in the future to ensure that there is an actual performance enhancing benefit.

186. Hard, supra note 7, at 548.

187. Gretchen Reynolds, Phys Ed: Will Olympic Athletes Dope if They Know It Might Kill Them?, N.Y. TimeS: WeLL (Jan. 20, 2010), https://perma.cc/RB9K-GK5C.

188. Education \& Prevention, WORLD ANTI-DOPING AGENCY, https://perma.cc/T5W4-WR2W (last visited Nov. 9, 2020). 
robs athletes of precious freedoms, and the potential benefits of such a regime are not worth the costs. Striking a balance between respecting athletes' reasonable expectations of privacy, properly communicating the real risks that come with prohibited substances, and monitoring for athlete health is still a better way to address this concern than the WADA Code's current enforcement regime.

\section{ALTERNATE METHODS AND DETERRENTS TO STRENGTHEN U.S. ANTI-DOPING POLICIES}

As shown above in Part II, the drawbacks to the adoption of the WADA Code outweigh any benefits it would bring to increased doping deterrence in the U.S. sports leagues. Yet, there are still ways that U.S. leagues can strengthen their anti-doping policies and address concerns of conflicts of interest. A common criticism levelled at U.S. sports leagues is that "a truly effective anti-doping policy is not in [their] interest and thus, they are motivated to install a lenient and porous policy with many loopholes."189 The crux of this argument is that, because both owners and players theoretically benefit from doping, there is no real incentive for U.S sports leagues to vigorously enforce their anti-doping policies. Additionally, U.S. sports league athletes are unionized, and the National Labor Relations Act (NLRA) requires the employers and unionized employees to bargain "in good faith with respect to wages, hours, and other terms and conditions of employment." 190 The National Labor Relations Board (NLRB) has found that drug policies that require testing of employees is a subject that must be bargained over between the employer and a representative of the unionized employees. ${ }^{191}$ This means that any changes to the anti-doping policies of the U.S. sports leagues must be bargained over with the players' unions. This system stands in contrast to WADA, which "is an independent agency with the ability to unilaterally regulate doping without having to bargain with its members." ${ }^{192}$ The ability for players to help shape the same anti-doping policy to which they are subject is consistently seen as a weakness of U.S. sports leagues' policies; critics insist that because the policy requires mutual agreement with the players, it must not be as strong as a unilateral policy.

However, while conflicts of interest can naturally arise with regard to doping policy, collective bargaining should not be seen as a weakness because there is evidence that most U.S. athletes have a vested interest in a clean playing field. ${ }^{193}$ Still, the idea that a few athletes or the league may seek to subvert proper anti-doping policies, whether to avoid detection or to avoid punishment for a superstar player, is one that should be addressed. In fact, there is a way to address the conflict of interest in properly enforcing anti-doping policies while also continuing to adhere to the

189. Gandert \& Ronisky, supra note 12 , at 834.

190. NLRB v. Wooster Div. of Borg-Warner Corp., 356 U.S. 342, 348-49 (1958).

191. See, e.g., Johnson-Bateman Co., 295 N.L.R.B. 180, 182-83 (1989); Kysor/Cadillac, 307 N.L.R.B 598, 598-99 (1992), enforced, 9 F.3d 108 (6th Cir. 1993); Coastal Chem. Co., 304 N.L.R.B. 556, 567-68 (1991).

192. Gandert \& Ronisky, supra note 12.

193. Stiefel III, supra note 10 , at 1257. 
NLRA's requirements and taking athlete concerns into consideration. That solution is the creation of an independent American anti-doping agency to monitor the Big Three U.S. sport leagues.

\section{A. An Independent AMerican Agency}

There are several reasons why the adoption of an independent American antidoping agency makes sense. Having an independent organization "make anti-doping rules is the logical way to remedy the conflict of interest that afflicts the American anti-doping system." 194 This claim is generally advanced to support the idea of U.S. sports leagues joining WADA and adopting the WADA Code to combat doping. ${ }^{195}$ However, because of the NLRA and the requirement that employers collectively bargain with the unions, adopting the WADA Code is logistically difficult and not the ideal way to combat doping. Instead, the U.S. sports leagues could silence the criticisms of WADA Code proponents while showing they take anti-doping policy seriously by taking it upon themselves to establish an American independent agency that would monitor the leagues, without any input or oversight by league officials. This would continue to respect athlete privacy and be appropriately punitive, unlike the WADA Code, as it would maintain the collective bargaining system currently in place and avoid any dramatic alterations to current anti-doping policies. The agency would handle testing and conduct a sport-specific risk assessment to determine what the appropriate testing frequency should be. In addition, the agency would interface with the players' unions, just as the leagues currently do, to set the prohibited substances list, the length of punishments, and what testing would be used. As mentioned previously, there is the concern that allowing players' unions to voice their concerns will lead to weak doping sanctions and numerous loopholes. ${ }^{196}$ But these concerns are misplaced; in fact, there are studies that show that "the majority of MLB players do not support the use of performance enhancing substances and feel cheated by those who use them." 197 It is likely that that this sentiment carries over to the other U.S. sports leagues and that even if individual players have incentives to dope, these incentives do not necessarily carry over to the players' unions as a whole. Thus, it is still in players' unions' best interest to ensure that the anti-doping regulations are robust without being overly punitive or implicating privacy concerns.

There is also the criticism that collective bargaining ensures that anti-doping policies will always be one step behind, consistently unable to catch the newest forms of doping. ${ }^{198}$ One of the commonly cited examples of this is the slow implementation

194. Gandert \& Ronisky, supra note 12 , at 843.

195. WADA President, Craig Reedie, "has tried to persuade NFL Commissioner Roger Goodell to get football subject to the WADA code" and stated that "harmonization with the rest of the world is difficult" without at least aligning with the goals of the WADA Code. Harris, supra note 10.

196. Gandert \& Ronisky, supra note 12, at 837 ("These loopholes and ineffective regulations are caused by the fact that the Steroid Policy is negotiated through the collective bargaining process.").

197. Stiefel III, supra note 10, at 1257.

198. Gandert \& Ronisky, supra note 12, at 836 ("As long as the NFL addresses doping through the collective bargaining process, it will forever be on the losing side of a cat and mouse game with cheaters."). 
of hGH testing by the U.S. sports leagues. ${ }^{199}$ The U.S. sports leagues were regularly criticized for not testing athletes' blood for $\mathrm{hGH}^{200}$ but they cited the invasive nature of the test and concerns about the utility of the test as a reason for their slow implementation. ${ }^{201}$ Yet, animating player's concerns with hGH testing was that blood testing is much more invasive than urine testing. Because the U.S. leagues give players a voice at the table, players were able to properly weigh in on this and find a solution that addressed their concerns. Blood testing was eventually integrated into the NBA, the NFL, and MLB. As noted above, the nature of combatting doping means that the regulations are always a step behind. In light of this, it is preferable to allow athletes to have a say in these policies instead of allowing an agency to unilaterally impose restrictions and punishment in order to attempt the Herculean task of keeping up with doping technology. By continuing to allow athletes to have a say in anti-doping policies, we treat them as individuals deserving of privacy and bodily autonomy, instead of subjecting them to unilateral doping policies like the WADA Code, which athletes have decried as "[i]ntolerable harassment" and "very invasive." 202

This independent agency could also interface with WADA to ensure that they benefit from the institutional knowledge that WADA has and to keep up with new developments in doping. Although the drawbacks of the WADA Code outweigh the benefits for the U.S. leagues, WADA still has a wealth of information that an independent agency could benefit from, and U.S. sports leagues should look to WADA for guidance regarding their prohibited substance list and new technologies. For example, the agency can look at WADA's sport specific analysis to help inform their decisions regarding testing frequency and the substances for which they should be on the lookout. ${ }^{203}$ Additionally, the agency should incorporate other deterrent factors when crafting the suspension length that should come with a doping violation. Unlike WADA, which generally subjects athletes to an extremely harsh punishment of two to four years, the agency should consider an appropriate punishment for each sport. For example, the NFL-which has the lowest guaranteed money for its players - would likely have a different suspension length than MLB or the NBA, which also have more games per season. ${ }^{204}$ This would help to ensure that doping sanctions are not overly punitive and also theoretically maintain the deterrent effect

199. See, e.g., id.

200. See e.g., id. at 837 ("Whether it is because the NFLPA's motive is to advance its interest or not, the NFLPA does not want to address the apparently reliable HGH drug test."); WADA President Calls on Major League Baseball To Implement Human Growth Hormone Testing, WORLD ANTI-DOPING AGENCY (Mar. 18, 2010), https://perma.cc/V43Y-E2NX; Abbott, supra note 68.

201. See Stiefel III, supra note 10, at 1274 ("The utility of WADA's HGH testing has also come into question, particularly because no athletes have tested positive during the four years during which it has been used and research indicates WADA's test can only detect HGH use within the last twenty-four to forty-eight hours.")

202. Clarey, supra note 8; Serena Williams Against New Drug-Testing Rules, ESPN (Feb. 12, 2009), https://perma.cc/W39X-JJJ8.

203. See World Anti-Doping Agency, WADA Technical Document For Sport SPecific ANALYSIS (Nov. 15, 2017), https://perma.cc/6ZWX-PM2C.

204. See Cork Gaines, NFL Salaries Still Trail MLB and NBA by a Wide Margin, BUS. INSIDER (July 15, 2015), https://perma.cc/H7PP-7ENK. 
that sanctions are generally believed to have. Additionally, it is important to think about the context in doling out these punishments, including the extent to which an athlete's decision to dope was coerced - as evidenced in the Russia cheating scandal, where "[a]thletes not initially willing to use pharmaceuticals were coerced to do so."205 Ultimately, in order to develop a comprehensive anti-doping policy, the proposed independent American agency should recognize that sanctions by themselves are likely not deterrent enough to prevent athletes from doping in all circumstances. As discussed below, the independent agency should also identify potentially more effective avenues to help supplement the overall goal of deterring doping.

\section{B. Other Deterrents To Consider}

Another criticism of WADA is that the strict liability system is simultaneously too harsh and not actually deterrent enough. Indeed, "[a]lthough bans have severe consequences that may lead to the sudden end of a career, studies show that these possibilities are not assessed as highly probable by athletes."206 This means that the strict liability system really ends up hurting athletes who unintentionally ingest contaminated substances but who do not fall under the category of No Significant Fault or Negligence, which is almost all of the athletes. ${ }^{207}$ The U.S. sports leagues similarly apply a system of strict liability, but WADA's lengthy suspensions combined with the strict liability are what make the Code particularly unfair to athletes. Whether athletes who are not as diligent as possible in monitoring their supplements should be punished is certainly a debatable topic; but it seems clear that even the threat of harsh sanctions under the WADA Code is not as much of a deterrent as WADA proponents would hope. Certainly, some proponents of more stringent anti-doping policies believe that "even the two-year mandatory penalties for a first doping offence [is] not a large enough of a deterrent." ${ }^{208}$ However, the answer should not be to enact harsher penalties for the sake of enacting harsher penalties, but rather, to look at the potential deterrents and whether those suffice. One such non-suspension related deterrent is the monetary fine-an economic deterrent. There are currently strong economic deterrents to doping, but they are inconsistently applied. As such, in order for the independent American agency to establish an optimal economic deterrent, it must craft a policy that is consistently applied, and severe enough to deter doping.

205. Editorial Board, Russia's Doping Game Gets Exposed, WASH. Post (Nov. 9, 2015), https://perma.cc/5T76-D5FY.

206. Daniel Westmattlemann, Dennis Dreiskämper, Bernd Strauß, Gerhard Schewe \& Jonas Plass, Perception of the Current Anti-doping Regime - A Quantitative Study Among German Top-Level Cyclists and Track and Field Athletes, 9 FRONTIERS PSYCH. 1, 4 (2018); see also generally Terry Engelberg, Stephen Moston \& James Skinner, The Final Frontier of Anti-Doping: A Study of Athletes Who Have Committed Doping Violations, 18 Sport MGMT. Rev. 268 (2015); Twan Huybers \& Jason Mazanov, What Would Kim Do: A Choice Study of Projected Athlete Doping Considerations, 26 J. SporT MGMT. $322(2012)$.

207. See definition of "No Significant Fault or Negligence" supra note 30.

208. Gandert, supra note 7, at 304. 
One postulate of game theory is that athletes will cheat when the payoff from cheating exceeds the penalty if caught, multiplied by the probability of being caught. $^{209}$ Based on the previous studies, the payoff will always exceed the penalty multiplied by probability, because most athletes do not assign a very high probability to being caught. This may be true if we consider just the WADA Code and its punishments; but if we increase the scope to economic and reputational harm, this formula may change. The independent agency would be tasked with interfacing with the players' unions to carefully tailor sanctions that would consider these harms to avoid being overly punitive with unnecessarily lengthy sanctions, like the WADA Code.

\section{Increased Fines}

The independent agency should also take into account the potential deterrent effect of levying additional fines on top of a suspension. Studies have shown that higher fines can have a stronger deterrent effect than suspensions, so it may be more valuable to increase fines than to lengthen suspensions. ${ }^{210}$ Missing games, while also getting a higher fine, may have a stronger deterrent effect than a suspension alone. This is borne out anecdotally by baseball superstar Alex Rodriguez, who noted that the most frustrating thing about his PED suspension was that it "cost [him] over $\$ 40$ million." 211 More research is certainly needed to determine what amount of fine would effectively deter - as this would depend heavily on the sport and the salaries of the athletes-but it is worth considering. The fines should take into account the amount of salary lost based on the suspension and assess what sort of additional fine should be levied in order to achieve maximum deterrent effect. For example, in the NFL, a first positive test result for an anabolic agent is six regular and/or postseason games, which accounts for about $38 \%$ of the regular season. ${ }^{212}$ As the NFL provides athletes the lowest guaranteed salary of the three major U.S. sports leagues, this economic penalty is already quite heavy, so whether further increase is needed to deter would need to be further explored. ${ }^{213}$ However, adding an additional fine on top of the games suspended could likely deter athletes from offending without threatening to take away years of their playing career. Accounting for the economic deterrents should be required under the independent American agency's anti-doping policy, and to increase deterrence, a subsequent increase in fines may be necessary.

209. Aleksander Berentsen, The Economics of Doping, 18 EUR. J. POL. ECON. 109, 111-12 (2002).

210. See Huybers \& Mazanov, supra note 206.

211. Alex Rodriguez on PED Suspension: "How Stupid Can You Be?," ESPN (Oct. 14, 2017), https://perma.cc/EJ2S-RC2J.

212. NFL Policy, supra note 25 , at 5 .

213. Id. It should be noted that the NFL and the NFL Players' Association recently increased the first-time penalty for anabolic steroids from four games to six games. Whether this will have an increased deterrent effect remains to be seen, but it certainly is quite an increase in terms of lost salary. 


\section{Reputational Harm: Loss of Endorsements and Enlistment of Sponsors}

Perhaps an even stronger claim for reputational harm as deterrence is the loss of endorsements that accompanies it. Lance Armstrong lost almost all of his endorsements, which Yahoo! Finance estimates cost him $\$ 150$ million. $^{214}$ Maria Sharapova, a tennis superstar who was suspended for two years in 2016 for taking a prohibited substance, lost major endorsements from Porsche, TAG Heuer, and Nike. ${ }^{215}$ These endorsements represent a different sort of fine inextricably linked to reputational harm. Endorsements often represent a larger portion of an athlete's income than the salary gained from their sports league; and in the case of Olympians, sponsorships can be the majority of their income. ${ }^{216}$ The guaranteed loss of an endorsement as a result of a doping violation would be a significant deterrent.

However, the problem with this approach is that sponsors are extremely inconsistent following a doping violation. Shortly after Maria Sharapova's suspension was handed down, Nike announced that it would actually continue Sharapova's sponsorship. ${ }^{217}$ Another example comes from Steve Magness, a former coach for the Oregon Project: an elite training group created by Nike for runners. Magness was one of the key whistleblowers leading to the program being shut down for doping. According to Magness:

If sponsors said "we are never going to support anyone who tests positive, never supporting coaches who have or have had athletes who take drugs, never supporting agents who have supported drugged athletes" ... [t] hey could snap their fingers and that would eliminate a huge part of the problem. ${ }^{218}$

As sponsorships will likely bring in income for athletes after their playing career is over, they would likely be much more cognizant of the risk of losing a major sponsor than loss of salary alone. This is arguably a better area for anti-doping policies to focus on. If WADA or U.S. sports leagues (or the proposed independent agency) could convince sponsors to sign on to commit to dropping athletes that end up with doping violations, this could achieve the deterrent effect that these antidoping policies aim to achieve. This would obviously not be done through force or mandate, but it could be framed as a PR event or as a commitment to a clean sport. While there is clearly no way to ensure that sponsors follow through, an independent

214. Andrew Lisa, 24 Athletes Who Lost Their Huge Endorsement Deals, YAHOo! FIN. (Aug. 14, 2019), https://perma.cc/NU6R-APVB.

215. Kevin Mitchell, Maria Sharapova Receives Two-Year Ban for Failing Drug Test, GuARDIAN (June 8, 2016), https://perma.cc/J57M-792B; Merrit Kennedy, Sharapova Loses Major Sponsors After Positive Drug Test, NPR (Mar. 8, 2016), https://perma.cc/4YKV-FA4A.

216. Kurt Badenhausen, World's Highest-Paid Athletes 2019, ForBes (June 11, 2019), https://perma.cc/877B-ZTEM; Mae Anderson, Olympics Stars Are Changing the Sponsorship Game, CHI. TRIB. (Feb. 16, 2018), https://perma.cc/5VEV-L9UP.

217. Sara Germano, Nike Will Continue Its Sponsorship of Maria Sharapova, Wall ST. J. (June 8, 2016), https://perma.cc/5EJD-7JRZ.

218. Mitch Phillips, Sponsors Missing from Action in War on Doping: Whistleblower, REUTERS (Aug. 12, 2016), https://www.reuters.com/article/us-olympics-rio-athletics-magness/sponsors-missingfrom-action-in-war-on-doping-whistleblower-idUSKCN10N170. 
agency would clearly have more leeway to push for such an agreement because they would not be linked with any sports leagues.

Establishing an American independent agency to monitor the NBA, MLB, and NFL, and enlisting sponsors to join the fight against doping, could address many of the concerns that are levied against U.S. anti-doping policies. Considering the steep penalties and the privacy concerns that accompany joining the WADA Code, an independent American anti-doping agency is the best way to strengthen anti-doping policies without also taking on WADA's many drawbacks.

\section{CONCLUSION}

Sports doping is incredibly difficult to catch and even more difficult to properly deter because doping methods are always one step in front of the testing procedures. Athletes have been "quoted boasting that 'when they get a test for that [new doping substance] we'll find something else. It's like cops and robbers." 219 Thus, the outstanding question is how far should sports leagues go to catch doping athletes? Doping is not a severe enough problem to justify constant monitoring and the strict liability sanctions that arise under the WADA Code. Additionally, it is unclear how one would even determine whether the Code is sufficiently more effective such that adoption by the NBA, the NFL, or MLB is warranted. The substantial weight of these outstanding questions and concerns demonstrates that the NBA, the NFL, and MLB should not adopt the WADA Code.

However, this is not to say that doping should not be combatted or deterred, or that the U.S. sports leagues anti-doping policies require no reform. To address the conflicts of interest issues inherent in the current system, an independent agency should be created to step into the shoes of the Big Three and liaise with players' unions to set anti-doping policies without needing to accept the drawbacks that come with the WADA Code. Doping regulations should focus on protecting the health of athletes and on deterrence methods beyond lengthy suspensions. These methods could take the form of increased fines or the enlistment of sponsors to assist in antidoping policies. The implementation of these strategies would lead to an amenable balance between athlete privacy and effective deterrence.

219. Richard H. McLaren, WADA Drug Testing Standards, 18 MARQ. SPORTS L. REV. 1, 3 (2007). 